\title{
Distinctive Changes in Plasma Membrane Phosphoinositides Underlie Differential Regulation of TRPV1 in Nociceptive Neurons
}

\author{
Viktor Lukacs, ${ }^{1}$ Yevgen Yudin, ${ }^{1}$ Gerald R. Hammond, ${ }^{2}$ Esseim Sharma, ${ }^{1}$ Kiyoko Fukami, ${ }^{3}$ and Tibor Rohacs ${ }^{1}$ \\ ${ }^{1}$ Department of Pharmacology and Physiology, Rutgers-New Jersey Medical School, Newark, New Jersey 07103, 2Section on Molecular Signal Transduction, \\ National Institute of Child Health \& Human Development, Bethesda, Maryland 20892, and ${ }^{3}$ Laboratory of Genome and Biosignal, Tokyo University of \\ Pharmacy and Life Sciences, Tokyo, Japan
}

Transient Receptor Potential Vanilloid 1 (TRPV1) is a polymodal, $\mathrm{Ca}^{2+}$-permeable cation channel crucial to regulation of nociceptor responsiveness. Sensitization of TRPV1 by G-protein coupled receptor (GPCR) agonists to its endogenous activators, such as low $\mathrm{pH}$ and noxious heat, is a key factor in hyperalgesia during tissue injury as well as pathological pain syndromes. Conversely, chronic pharmacological activation of TRPV1 by capsaicin leads to calcium influx-induced adaptation of the channel. Paradoxically, both conditions entail activation of phospholipase C (PLC) enzymes, which hydrolyze phosphoinositides. We found that in sensory neurons PLC $\beta$ activation by bradykinin led to a moderate decrease in phosphatidylinositol-4,5-bisphosphate $\left(\mathrm{PI}(4,5) \mathrm{P}_{2}\right)$, but no sustained change in the levels of its precursor PI(4)P. Preventing this selective decrease in PI $(4,5) \mathrm{P}_{2}$ inhibited TRPV1 sensitization, while selectively decreasing $\mathrm{PI}(4,5) \mathrm{P}_{2}$ independently of PLC potentiated the sensitizing effect of protein kinase C (PKC) on the channel, thereby inducing increased TRPV1 responsiveness. Maximal pharmacological TRPV1 stimulation led to a robust decrease of both $\mathrm{PI}(4,5) \mathrm{P}_{2}$ and its precursor $\mathrm{PI}(4) \mathrm{P}$ in sensory neurons. Attenuating the decrease of either lipid significantly reduced desensitization, and simultaneous reduction of $\mathrm{PI}(4,5) \mathrm{P}_{2}$ and PI(4)P independently of PLC inhibited TRPV1. We found that, on the mRNA level, the dominant highly $\mathrm{Ca}^{2+}$-sensitive PLC isoform in dorsal root ganglia is PLC84. Capsaicin-induced desensitization of TRPV1 currents was significantly reduced, whereas capsaicininduced nerve impulses in the skin-nerve preparation increased in mice lacking this isoform. We propose a comprehensive model in which differential changes in phosphoinositide levels mediated by distinct PLC isoforms result in opposing changes in TRPV1 activity.

\section{Introduction}

The $\mathrm{Ca}^{2+}$-permeable nonselective cation channel Transient Receptor Potential Vanilloid 1 (TRPV1) is a key regulator of nociceptor responsiveness because of its polymodal activation profile by protons, heat, endovanilloids, and other proinflammatory lipid metabolites, such as eicosanoids (Tominaga et al., 1998). These agents synergistically activate the channel, whereas a plethora of other components of the "inflammatory soup" act indirectly via second-messenger pathways to potentiate TRPV1 responses (Hucho and Levine, 2007). The importance of this channel in inflammatory sensitization was demonstrated by decreased inflammation and thermal hyperalgesia in TRPV1

Received Dec. 10, 2012; revised April 18, 2013; accepted May 6, 2013.

Author contributions: V.L. and T.R. designed research; V.L., Y.Y., and E.S. performed research; G.R.H. and K.F. contributed unpublished reagents/analytic tools; V.L., Y.Y., and T.R. analyzed data; V.L. and T.R. wrote the paper.

T.R. was supported by National Institutes of Health Grants R01NS055159 and R01GM093290. The authors thank Dr. Tamas Balla (National Institutes of Health) for insightful comments and for providing the 0sh2-PH-GFP clone, Dr. David Julius for providing the TRPV1 clone, Dr. Yasushi Okamura (Osaka University, Japan) for providing the ci-VSP and dr-VSP clones, Drs. Nikita Gamper (University of Leeds) and Andrew Tinker (University College London) for providing the tubby- R332H-YFP clone, and Linda Zabelka for maintaining the mouse colony.

The authors declare no competing financial interests.

Correspondence should be addressed to Dr. Tibor Rohacs, Department of Pharmacology and Physiology, RutgersNew Jersey Medical School, 185 South Orange Avenue, Newark, New Jersey 07103. E-mail: rohacsti@njms.rutgers.edu. DOl:10.1523/JNEUROSC1.5637-12.2013

Copyright $\odot 2013$ the authors $\quad 0270-6474 / 13 / 3311451-13 \$ 15.00 / 0$ knock-out animals (Caterina et al., 2000). Many of the proinflammatory mediators induce sensitization of TRPV1 through the activation of PLC. An important established element in this pathway is phosphorylation of the channel by protein kinase $\mathrm{C}$ (PKC), which is activated downstream of PLC and is an important mediator of increased nociceptor excitability (Cesare et al., 1999; Bhave et al., 2003).

Paradoxically, robust and long-lasting local pharmacological activation of TRPV1 by saturating capsaicin concentrations leads to analgesia (Szolcsanyi, 2004), which is thought to be mediated, at least in part, by the desensitization of TRPV1 itself (Koplas et al., 1997). Such activation of TRPV1 results in massive $\mathrm{Ca}^{2+}$ influx through the channel, which is the key factor inducing desensitization. Intriguingly, it has been demonstrated that $\mathrm{Ca}^{2+}$ entry via TRPV1 also activates PLC (Lukacs et al., 2007; Yao and Qin, 2009). This prompts the question: how do these seemingly converging pathways result in such strikingly opposite outcomes in terms of their effect on TRPV1?

Hydrolysis of $\mathrm{PI}(4,5) \mathrm{P}_{2}$ by PLC leads to formation of inositol 1,4,5-trisphosphate $\left(\mathrm{IP}_{3}\right)$ and diacylglycerol (DAG). The former releases $\mathrm{Ca}^{2+}$ from internal stores; the latter activates PKC. $\mathrm{PI}(4,5) \mathrm{P}_{2}$, in its own right, is also a general regulator of many different mammalian ion channels (Logothetis and Nilius, 2007; Suh and Hille, 2008; Gamper and Rohacs, 2012), including TRP channels (Nilius et al., 2008; Rohacs, 2009). TRPV1 was originally 
proposed to be inhibited by $\mathrm{PI}(4,5) \mathrm{P}_{2}$ (Chuang et al., 2001), but later studies showed that $\mathrm{PI}(4,5) \mathrm{P}_{2}$ chelating agents inhibit capsaicin-induced TRPV1 currents in excised patches while resupplying $\mathrm{PI}(4,5) \mathrm{P}_{2}$ or its precursor $\mathrm{PI}(4) \mathrm{P}$ to the cytoplasmic leaflet of the patch membrane reactivates the channel (Stein et al., 2006; Lukacs et al., 2007; Klein et al., 2008). Nevertheless, an inhibitory effect of $\mathrm{PI}(4,5) \mathrm{P}_{2}$ has also been suggested by several recent publications (Lukacs et al., 2007; Jeske et al., 2011; Cao et al., 2013).

In the present work, we attempted to resolve these controversies by studying the changes in phosphoinositide levels during $\mathrm{Ca}^{2+}$ influx through TRPV1 and GPCR activation and measuring TRPV1 activity in response to alterations in phosphoinositide levels. We show that $\mathrm{Ca}^{2+}$ entry upon maximal pharmacological stimulation of TRPV1 results in robust $\mathrm{PI}(4) \mathrm{P}$ and $\mathrm{PI}(4,5) \mathrm{P}_{2}$ breakdown via activation of PLC $\delta$ isoforms and leads to TRPV1 inhibition. In contrast, bradykinin receptor activation leads to a selective $\mathrm{PI}(4,5) \mathrm{P}_{2}$ decrease, which synergizes with the sensitizing effect of phosphorylation by PKC. This leads to potentiation of TRPV1 currents, contributing to inflammatory TRPV1 sensitization.

\section{Materials and Methods}

Cell isolation and culture. All animal procedures were approved by the Institutional Animal Care and Use Committee. Dorsal root ganglion (DRG) neurons were isolated from 2- to 4-month-old wild-type C57BL6 or PLC $84^{-1-}$ (Fukami et al., 2001) (C57BL6 background) mice as described previously (Yudin et al., 2011) with some modifications. DRG neurons were isolated from mice of either sex anesthetized and perfused via the left ventricle with ice-cold Hank's buffered salt solution (HBSS; Invitrogen). DRGs were harvested from all spinal segments after laminectomy and removal of the spinal column and maintained in ice-cold HBSS for the duration of the isolation. Isolated ganglia were cleaned from excess dorsal root nerve tissue and incubated in an HBSS-based enzyme solution containing $2 \mathrm{mg} / \mathrm{ml}$ type I collagenase (Worthington) and $5 \mathrm{mg} / \mathrm{ml}$ Dispase (Sigma) at $37^{\circ} \mathrm{C}$ for $25 \mathrm{~min}$, followed by mechanical trituration by repetitive pipetting through an uncut $1000 \mu$ l pipette tip. Digestive enzymes were then removed after centrifugation of the cells at $80 \times g$ for $10 \mathrm{~min}$. Cells were then either directly resuspended in growth medium and seeded onto glass coverslips coated with a mixture of polyD-lysine (Invitrogen) and laminin (Sigma) or were first transfected using the Amaxa nucleoporator according to manufacturer's instructions (Lonza Walkersville). Briefly, 60,000-100,000 cells obtained from each animal were resuspended in $100 \mu \mathrm{l}$ nucleofector solution after complete removal of digestive enzymes. Cells were then mixed with $2 \mu \mathrm{g}$ of either YFP-Tubby R332H-pCDNA3.1 or Osh2-tandem-pH-pEGFP-C1, electroporated using the Nucleofector II apparatus and seeded as described above. The cDNA used for transfecting neurons was prepared using the Endo-Free Plasmid Maxi Kit from QIAGEN. Neurons were maintained in culture for 16-24 h before measurements in DMEM (DMEM:F12) supplemented with 10\% FBS (Thermo Scientific), $100 \mathrm{IU} / \mathrm{ml}$ penicillin and $100 \mu \mathrm{g} / \mathrm{ml}$ streptomycin.

Human embryonic kidney 293 (HEK293) cells were obtained from the ATCC and were cultured in minimal essential medium (Invitrogen) containing supplements of $10 \%(\mathrm{v} / \mathrm{v})$ Hyclone-characterized FBS (Thermo Scientific), $100 \mathrm{IU} / \mathrm{ml}$ penicillin, and $100 \mu \mathrm{g} / \mathrm{ml}$ streptomycin. Transient transfection was performed at $\sim 70 \%$ cell confluence with the Effectene reagent (QIAGEN) according to the manufacturer's protocol. Cells were incubated with the lipid-DNA complexes overnight (12-15 h). We then trypsinized and replated the cells onto poly-D-lysine-coated glass coverslips and incubated them for an additional $24 \mathrm{~h}$ (in the absence of the transfection reagent) before measurement. All mammalian cells were kept in a humidity-controlled tissue-culture incubator maintaining 5\% $\mathrm{CO}_{2}$ at $37^{\circ} \mathrm{C}$. Before each experiment, cells were serum-deprived in 1.25 $\mathrm{mM} \mathrm{Ca}^{2+}$-containing standard extracellular buffer for at least $15 \mathrm{~min}$.

Xenopus laevis oocytes were harvested and maintained identically to that described previously (Lukacs et al., 2007).
Electrophysiology. Whole-cell patch-clamp recordings were performed at room temperature $\left(22-24^{\circ} \mathrm{C}\right)$ as described previously (Yudin et al., 2011). Patch pipettes were pulled from borosilicate glass capillaries (1.75 mm outer diameter, Sutter Instruments) on a P-97 pipette puller (Sutter Instrument) to a resistance of 4-6 M $\Omega$. After formation of gigaohmresistance seals, the whole-cell configuration was established and currents were measured at a holding potential of $-60 \mathrm{mV}$ using an Axopatch 200B amplifier (Molecular Devices). Currents were filtered at $2 \mathrm{kHz}$ using the low-pass Bessel filter of the amplifier and digitized using a Digidata 1440 unit (Molecular Devices). In some experiments, membrane potential pulses of indicated lengths to $100 \mathrm{mV}$ were applied to activate the voltage-sensitive phosphatase (Dr-VSP). Measurements were conducted in solutions based on nominally $\mathrm{Ca}^{2+}$-free (NCF) medium containing the following (in $\mathrm{mM}$ ): $137 \mathrm{NaCl}, 4 \mathrm{KCl}, 1 \mathrm{MgCl}_{2}, 5$ HEPES, 5 MES, 10 glucose, $\mathrm{pH}$ adjusted to 7.4 with $\mathrm{NaOH}$. For measurements on DRG neurons, NCF was complemented with $\mathrm{CaCl}_{2}$ to a final concentration of $1.25 \mathrm{~mm}$. For experiments in HEK293 cells, 5 mM EGTA was added to the extracellular solution to prevent rapid current desensitization. Intracellular solutions for DRG measurements (NIC-DRG) consisted of the following (in mM): $130 \mathrm{~K}$-Gluconate, $10 \mathrm{KCl}, 2 \mathrm{MgCl}_{2}, 2$ $\mathrm{Na}_{2} \mathrm{ATP}, 0.2 \mathrm{Na}_{2} \mathrm{GTP}, 1.5 \mathrm{CaCl}_{2}$, 2.5 EGTA, 10 HEPES, pH adjusted to 7.25 with $\mathrm{KOH}$. Intracellular solutions for HEK293 whole-cell measurements were as follows. In experiments without coexpressed Kir2.1 channels, we used our standard intracellular (NIC) solution consisting of the following (in mM): $130 \mathrm{KCl}, 10 \mathrm{KOH}, 3 \mathrm{MgCl}_{2}, 2 \mathrm{Na}_{2} \mathrm{ATP}, 0.2 \mathrm{Na}_{2} \mathrm{GTP}$, $0.2 \mathrm{CaCl}_{2}, 2.5$ EGTA, 10 HEPES, pH adjusted to 7.25 with $\mathrm{KOH}$. For measurements with coexpression of Kir2.1, cesium chloride-based intracellular solutions (Cs-IC) were used that consisted of the following (in mM): $130 \mathrm{CsCl}, 10 \mathrm{CsOH}, 3 \mathrm{MgCl}_{2}, 2 \mathrm{Na}_{2} \mathrm{ATP}, 0.2 \mathrm{Na}_{2} \mathrm{GTP}, 2.5$ EGTA, 10 HEPES, pH adjusted to 7.25 with $\mathrm{CsOH}$. The $\mathrm{diC}_{8}$-lipids or the $\mathrm{PKC}$ inhibitor peptide were dissolved in $\mathrm{H}_{2} \mathrm{O}$; thus, their addition to the pipette solution decreased osmolarity $\sim 4 \%$. Therefore, in these measurements, control pipette solution osmolarity was adjusted with deionized water. The equivalent concentration of $\mathrm{diC}_{-}{ }_{8} \mathrm{PI}(4,5) \mathrm{P}_{2}$ to that of endogenous $\mathrm{PI}(4,5) \mathrm{P}_{2}$ in the plasma membrane was reported to be $\sim 23 \mu \mathrm{M}$ based on comparison of cell-attached and excised inside-out patchclamp measurements (Li et al., 2005). To ensure that the lipids added to the pipette solution will approach this concentration inside the cell, given the small diameter of the tip of the pipette and potential metabolism of the lipid inside the cell, we used $100 \mu \mathrm{M}$ of the $\mathrm{diC}_{8}$ phosphoinositides. Series resistance was not compensated for whole-cell measurements; measurements with access resistances 5-15 $\mathrm{M} \Omega$ were used for analysis.

Perforated patch-clamp measurements on DRG neurons were conducted using a pipette solution containing the following (in $\mathrm{mm}$ ): 130 K-Gluconate, $10 \mathrm{KCl}, 1 \mathrm{MgCl}_{2}, 10 \mathrm{HEPES}, 0.1$ Indo- 1 potassium salt, 0.75 amphotericin $\mathrm{B}, \mathrm{pH}$ adjusted to 7.35 with $\mathrm{KOH}$. Series resistance compensation was used, and perforated patches yielding access resistances 3-10 M $\Omega$ were used for analysis. Access resistances were checked before and after each capsaicin pulse. After each measurement, the distribution of the cell impermeable Indo- 1 dye was recorded using the epifluorescence imaging system described below. Measurements where dialysis of the dye into the cell occurred (break-in by Amphotericin B resulting in a whole-cell setting) were discarded.

Extracellular recordings in the skin-nerve preparation. The mouse isolated skin-saphenous nerve preparation and the single-fiber recording technique (Zimmerman et al., 2009) were performed as previously described (Yudin et al., 2004) with some modifications. In brief, the skin of the lower part of the hindpaw of adult mice of either sex (weighing 20-25 g, age 2-3 months) was dissected subcutaneously together with the attached saphenous nerve under ketamine-xylazine intraperitoneal anesthesia. The skin was pinned corium side up in an organ chamber and perfused $(10 \mathrm{ml} / \mathrm{min})$ with temperature-controlled $\left(32^{\circ} \mathrm{C}\right)$ synthetic interstitial fluid, containing (in mM): $128 \mathrm{NaCl}, 1.9 \mathrm{KCl}, 1.2 \mathrm{KH}_{2} \mathrm{PO}_{4}, 0.69$ $\mathrm{MgSO}_{4}, 25 \mathrm{NaHCO}_{3}, 1.54 \mathrm{CaCl}_{2}$, and 10 glucose, $\mathrm{pH} 7.4 \pm 0.1$ carbogenated with $\mathrm{O}_{2}-\mathrm{CO}_{2}$ mix of $95 \%$ and $5 \%$, respectively. The saphenous nerve was drawn through a small hole into a separate recording chamber filled with mineral oil, desheathed, and small filaments of the nerve were split with sharp forceps and thin needles. Monopolar recordings from single afferent C-fibers were performed. Receptive fields of the single 
units were identified by mechanical stimulation of the corium side of the skin with a blunt glass probe. Conduction velocity of the individual unit was determined by applying electrical pulses to the receptive field via a tungsten needle electrode and was calculated from the delay of the individual action potential spikes and the distance between the stimulating and recording electrodes. A cutoff velocity of $1.2 \mathrm{~m} / \mathrm{s}$ was used to identify C-fibers.

For chemical stimulation, a stock solution of capsaicin $(10 \mathrm{~mm})$ in $100 \%$ ethanol was diluted in $32^{\circ} \mathrm{C}$ synthetic interstitial fluid buffer just before application. Capsaicin was applied to the receptive field, which was isolated with a metal ring ( $5 \mathrm{~mm} \mathrm{ID,} 200-300 \mu$ linternal volume) that was sealed to the corium side of the skin with a thin layer of vacuum grease. Only fibers with nonoverlapping receptive fields were used from the same skin preparation. We used a higher final capsaicin concentration $(10 \mu \mathrm{M})$ than in the patch-clamp experiments $(1 \mu \mathrm{M})$, as customary in these experiments, because the drug needs to penetrate tissue layers to reach the nerve terminals (Zimmermann et al., 2009).

Action potentials were amplified (A-M System 1800) and filtered using the built in filters of the amplifier, $100 \mathrm{~Hz}$ for low and $10 \mathrm{kHz}$ for high frequencies, and continuously recorded and processed on a computer using the DataWave software (Datawave Technologies). PLC $\delta 4^{-/-}$and wild-type littermate mice were recorded in random order, and the investigator was blinded to their genotype.

Fluorescence imaging. $\mathrm{Ca}^{2+}$ imaging measurements were performed with an Olympus IX-51 inverted microscope equipped with a DeltaRAM excitation light source (Photon Technology International). DRG neurons were loaded with $1 \mu \mathrm{M}$ fura-2 AM (Invitrogen) or $1 \mu \mathrm{M}$ fura-2 FF (Teflabs) for $30 \mathrm{~min}$ before the measurement, and dual-excitation images at 340 and $380 \mathrm{~nm}$ were recorded with a Roper Cool-Snap digital CCD camera. Measurements were conducted in normal NCF solution supplemented with $1.25 \mathrm{~mm} \mathrm{CaCl}_{2}$. Data analysis was performed using the Image Master software (PTI).

Confocal measurements were conducted with a Nikon A1R-A1 confocal laser microscope system. DRG neurons were transfected 16-24 h before confocal measurements with the fluorescent reporter constructs. Confocal images were collected using the NIS-Elements imaging software and pseudo-colored at the point of image analysis (yellow for YFPTubby and green for GFP-Osh2). Membrane to cytoplasm fluorescence ratios were calculated by selection of identically sized plasma membrane and cytosolic regions on confocal images using ImageJ (http://rsbweb. nih.gov/ij/). Alternatively, line graphs at the level of processes were generated showing arbitrary fluorescence values along the lines indicated.

Reverse-transcription and quantitative PCR. Total RNA from mouse DRG was isolated using the RNA-easy kit (QIAGEN) according to the manufacturer's instructions. Reverse transcription of mRNA was achieved using the Superscript III enzyme with Oligo $\mathrm{dT}_{20}$ primers (Invitrogen) according to instructions. Control reactions for genomic contamination contained no Superscript III enzyme.

Quantitative PCRs were run with an MX-3000 thermal cycler (Stratagene) using the SYBR Green-based Brilliant QPCR mix (Stratagene). Oligonucleotide primers for the highly calcium-sensitive PLC isoforms and the housekeeping gene ubiquitin were designed using primer 3 (http://frodo.wi.mit.edu/) and calibrated for efficiency using a serial dilution of cDNA transcribed from mouse brain mRNA. Only primers yielding a reaction efficiency close to $100 \%$ in our external calibrations were used for analysis of PLC expression patterns. The primer sequences were as follows $\left(5^{\prime}-3^{\prime}\right)$ : mUbiquitin (forward: GCCCAGTGTTACCACCAAGAAG; reverse: GCTCTTTTTAGATACTGTGGTG AGGAA); mPLC $\delta 1$ (forward: ATGTTTACCTTGGCTGCTTC; reverse: GAGATGATCCAGACTCTGAGC); mPLC $\delta 3$ (forward: AACTATAACCCCCAGGAGATG; reverse: AGGTAAGCAGGTTTGAGGAC); mPLC84 (forward: AATTCCTGAGAGATACCCAGAG; reverse: TCTTCAGGAACACCATAGAGC); mPLC $\eta 1$ (forward: TGAAAGTGGAACAAAAGATGAG; reverse: CGTGAAGCCTTCTATACCAA); and mPLC $\eta 2$ (forward: GAGGAGACACTGGTGTTCAC; reverse: AATGTCACTGACAGCCACAT).

Materials. $\mathrm{DiC}_{8}$ phosphoinositides were purchased from Cayman. Capsaicin, resiniferatoxin, rapamycin, bradykinin, and PKC inhibitor 19-31 amide were purchased from Sigma; 1-oleoyl-2-acetly- diacylglycerol (OAG) was purchased from Axxora. Stock solutions $(1000 \times$ concentration) for rapamycin were prepared in DMSO. Capsaicin, resiniferatoxin, and OAG stock were prepared in ethanol $(1000 \times$ concentration or higher). PKC inhibitor 19-31 amide stock was prepared in deionized water, and bradykinin was dissolved in an aqueous $5 \%$ acetate solution.

Data analysis. Data are presented as mean \pm SEM. Normality test was performed on all datasets using the Shapiro-Wilk test. Normally distributed data were analyzed for statistically significant differences using twosample Student's $t$ test or ANOVA, where applicable. Statistical analysis of data not showing normal distribution was done using the MannWhitney $U$ test (as indicated in Fig. 6).

\section{Results}

\section{$\mathrm{Ca}^{2+}$ influx via TRPV1 channels depletes both PI(4)P and $\mathrm{PI}(4,5) \mathrm{P}_{2}$ and leads to desensitization}

We expressed fluorescently labeled probes that bind different phosphoinositides and monitored their translocation using confocal microscopy in isolated DRG neurons. To track $\mathrm{PI}(4,5) \mathrm{P}_{2}$ changes in the plasma membrane, we used the YFP-tagged phosphoinositide binding domain of the Tubby protein containing the $\mathrm{R} 322 \mathrm{H}$ mutation that decreases its affinity for $\mathrm{PI}(4,5) \mathrm{P}_{2}$, thus increasing its sensitivity and dynamic range (Quinn et al., 2008). In separate experiments, we used the GFP-tagged tandem pleckstrin homology domain ( $\mathrm{PH}$ domain) of the yeast Osh2 protein to monitor PI(4)P levels in the plasma membrane (Balla et al., 2008). Isolated neurons transfected with either of these constructs showed prominent plasma membrane labeling. Importantly, after $12 \mathrm{~h}$ in culture, DRG neurons extended a rich network of neurites. This allowed for analysis of phosphoinositide changes in the physiologically relevant context of processes and their visible end bulbs or varicosities. TRPV1 opening in the presence of $1.25 \mathrm{~mm}$ extracellular $\mathrm{Ca}^{2+}$ induced robust translocation of both fluorescent probes from the plasma membrane to the cytoplasm in the cell body (Fig. $1 A, C$ ) as well as the neuronal processes (Fig. $1 B$ ). This translocation, when induced by a saturating capsaicin concentration $(1 \mu \mathrm{M})$, occurred rapidly (within $\sim 30-50 \mathrm{~s}$ ), whereas the ultra-potent agonist resiniferatoxin, a compound shown to activate TRPV1 with much slower kinetics (Raisinghani et al., 2005), induced similar translocation of both probes on a slower time scale (Fig. 1D).

We next asked whether $\mathrm{Ca}^{2+}$ influx was necessary for the depletion of phosphoinositides in DRG neurons. We therefore conducted experiments in the absence of extracellular $\mathrm{Ca}^{2+}$. As seen in Figure 2, $A$ and $B, 1 \mu \mathrm{M}$ capsaicin still induced a slight but statistically significant translocation of the Tubby domain to the cytoplasm when we chelated extracellular $\mathrm{Ca}^{2+}$ to zero. Importantly, readdition of $\mathrm{Ca}^{2+}$ to a final concentration of $1.25 \mathrm{~mm}$ resulted in a robust translocation similar to that in Figure 1. We have obtained similar results earlier with menthol and TRPM8 using a fluorescence resonance energy transfer-based approach, monitoring $\mathrm{PI}(4,5) \mathrm{P}_{2}$ with the CFP and YFP tagged $\mathrm{PH}$ domains of PLC 84 (Yudin et al., 2011).

Because TRPV1 activation also leads to depolarization, we tested whether $\mathrm{Ca}^{2+}$ entry via voltage-gated $\mathrm{Ca}^{2+}$ channels induced the phosphoinositide changes we observed. We used 30 $\mathrm{mm}$ extracellular $\mathrm{KCl}$ to mimic prolonged depolarization by TRPV1. KCl induced a translocation of both the Osh2 and Tubby domains (Fig. 2C,D) smaller in magnitude than that induced by capsaicin. In addition, $1 \mu \mathrm{M}$ capsaicin applied in the presence of $\mathrm{KCl}$ still induced a large additional translocation (Fig. 2C,D).

To determine whether the larger effect of capsaicin on lipid levels was the result of differences in cytoplasmic $\mathrm{Ca}^{2+}$, we com- 
A
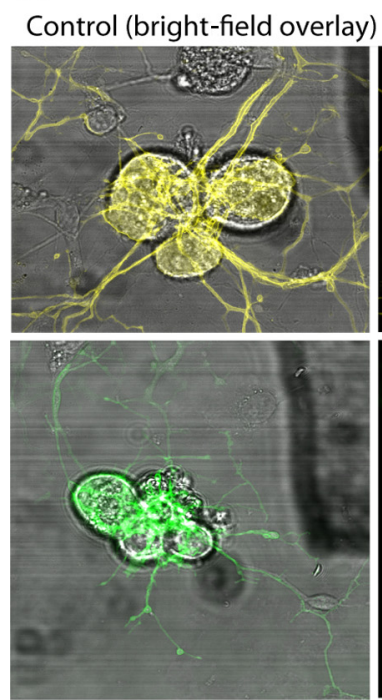

C

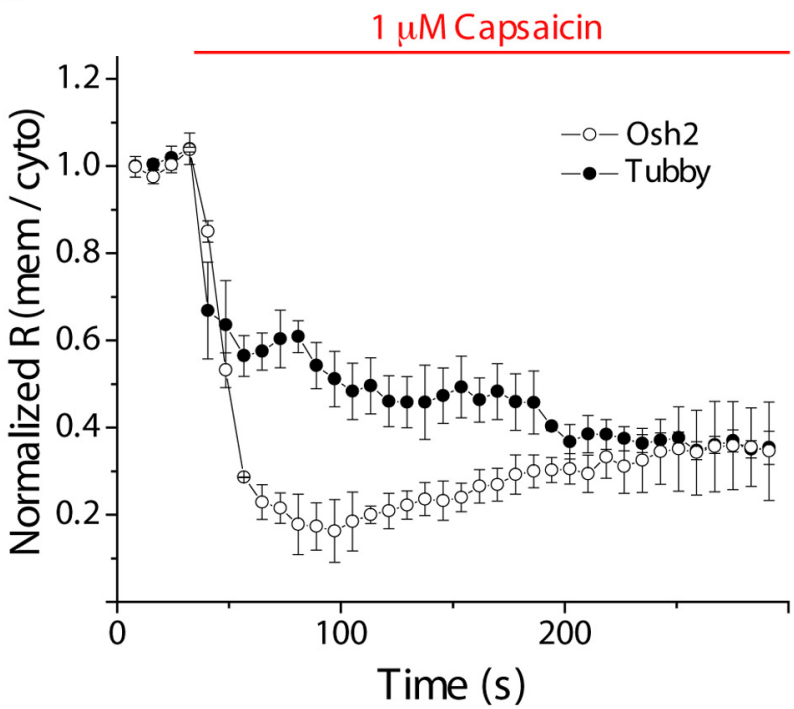

B
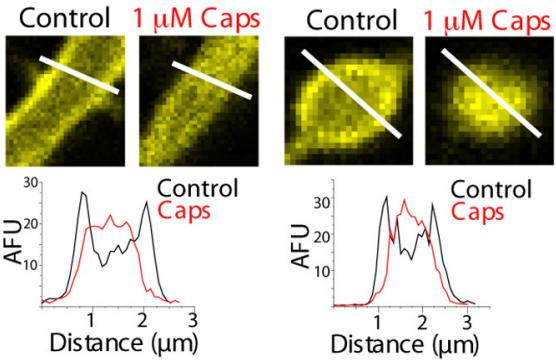

Control $1 \mu \mathrm{M}$ Caps

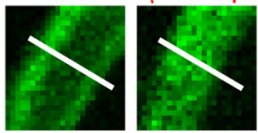

Control $1 \mu \mathrm{M}$ Caps

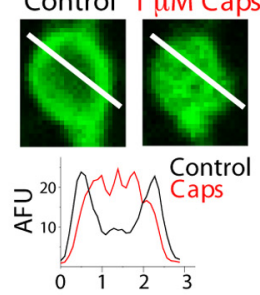

Distance $(\mu \mathrm{m})$

\section{D}

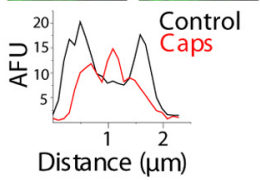

1 nM RTX

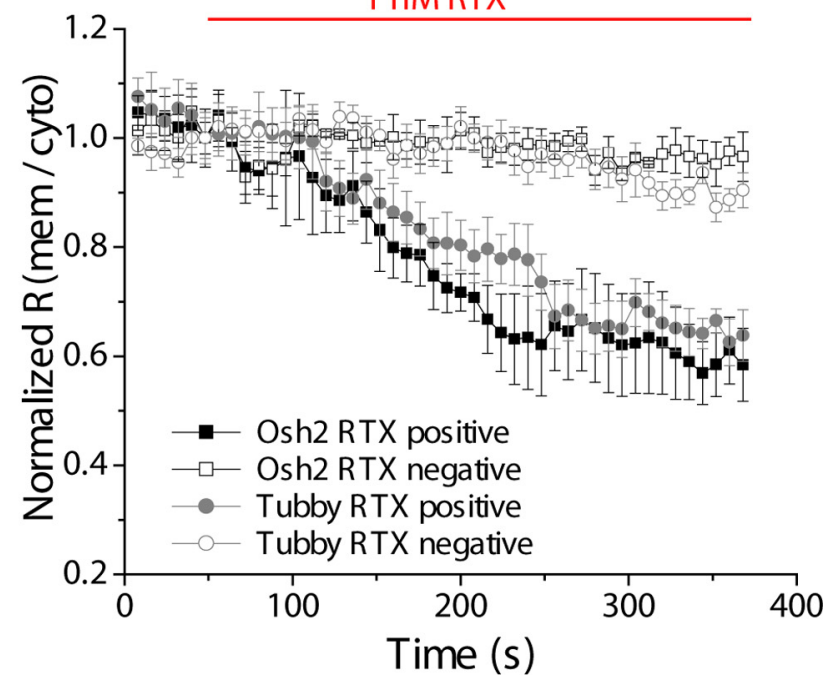

Figure 1. Capsaicin induces depletion of $\mathrm{PI}(4) \mathrm{P}$ and $\mathrm{PI}(4,5) \mathrm{P}_{2}$ in nociceptors. $A$, Confocal images of DRG neurons transfected with the YFP-tagged R322H Tubby domain (top, pseudo-colored yellow) or the GFP-tagged 0sh2 tandem-PH domain (bottom, pseudo-colored green) as reporters of plasma membrane phosphoinositides. Images are representatives of reporter distribution before and after the application of $1 \mu \mathrm{m}$ capsaicin (Caps). Scale bars, $10 \mu \mathrm{m}$. B, Magnified images of Tubby (top) and Osh2 (bottom) reporter localization before and after capsaicin application at the neurites (left) and varicosities (right) distant from the cell body indicated in $\boldsymbol{A}$ by arrowheads pointing at the regions magnified. The graph under each pair of magnified images corresponds to fluorescence intensities (in arbitrary fluorescence units [AFU]) plotted along the lines indicated in each image. C, Time course of membrane to cytoplasm fluorescence ratio changes for Tubby and 0sh2 reporters in response to treatments with $1 \mu \mathrm{m}$ capsaicin. Images were taken at $8 \mathrm{sintervals;}$; data points represent mean \pm SEM of normalized membrane to cytoplasm fluorescence ratios at the cell body ( $n=4$ or 5 neurons per group). $\boldsymbol{D}$, Time course of membrane to cytoplasm ratio changes for Tubby and 0sh2 in response to $1 \mathrm{~nm}$ resiniferatoxin (RTX) conducted identically to that described in C. Slow translocation of the fluorescent probes in a subset of neurons (RTX positive) is appreciable compared with neurons that displayed no response to RTX (RTX negative). Data points represent mean \pm SEM of $n=4-6$ neurons per group. All measurements were conducted in standard NCF solution supplemented with $1.25 \mathrm{~mm} \mathrm{CaCl}_{2}$ (see Materials and Methods).

pared the $\mathrm{KCl}$ - and capsaicin-induced $\mathrm{Ca}^{2+}$ signals in DRG neurons. Using fura- 2 as a $\mathrm{Ca}^{2+}$ indicator, we found that the increases of fluorescence ratio induced by $30 \mathrm{mM} \mathrm{KCl}$ and $1 \mu \mathrm{M}$ capsaicin were comparable (Fig. 2E, G). Fura-2, however, has a high affinity for $\mathrm{Ca}^{2+}\left(\mathrm{K}_{\mathrm{d}} \sim 100-200 \mathrm{nM}\right)$; thus, it is not a sensitive indicator at very high $\mathrm{Ca}^{2+}$ levels. We therefore tested the $\mathrm{Ca}^{2+}$ signals evoked by these two stimuli using a low-affinity $\mathrm{Ca}^{2+}$ indicator fura-2 FF ( $\left.\mathrm{K}_{\mathrm{d}} \sim 15-25 \mu \mathrm{M}\right)$. In cells loaded with fura- $2 \mathrm{FF}$, capsaicin induced a much larger increase in fluorescence ratio than in cells stimulated with $30 \mathrm{~mm} \mathrm{KCl} \mathrm{(Fig.} \mathrm{2F,G).} \mathrm{These} \mathrm{results} \mathrm{show} \mathrm{that}$ capsaicin induces a larger increase in cytoplasmic $\mathrm{Ca}^{2+}$ than $\mathrm{KCl}-$ induced depolarization, which may account for the larger effect of capsaicin on phosphoinositide depletion.
To test the role of the concomitant decrease of $\mathrm{PI}(4) \mathrm{P}$ and $\mathrm{PI}(4,5) \mathrm{P}_{2}$ in the regulation of TRPV1, we performed whole-cell voltage-clamp experiments on DRG neurons and supplemented the patch pipette solution with the water-soluble $\mathrm{diC}_{8}-\mathrm{PI}(4) \mathrm{P}$ or $\mathrm{diC}_{8}-\mathrm{PI}(4,5) \mathrm{P}_{2}$. We used a protocol of consecutive $1 \mathrm{~min}$ applications of $1 \mu \mathrm{M}$ capsaicin $5 \mathrm{~min}$ apart. We used this protocol to assess acute desensitization (the decrease of current amplitude in the continued presence of the stimulus) as well as tachyphylaxis (the decrease in peak amplitudes of consecutive applications), consistent with previous studies (Liu et al., 2005; Lukacs et al., 2007). Figure $3 A-C$ shows that intracellular dialysis of either lipid significantly impaired both acute desensitization and tachyphylaxis of TRPV1 currents. This is consistent with earlier findings 
A

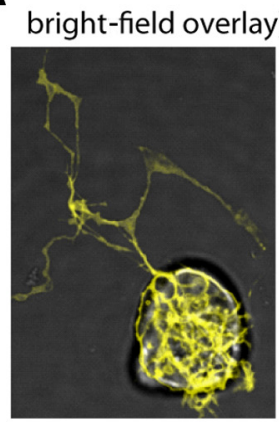

C
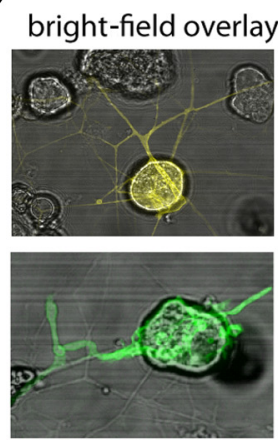

1

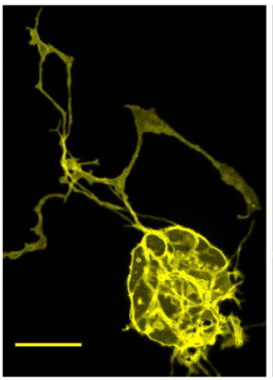

2
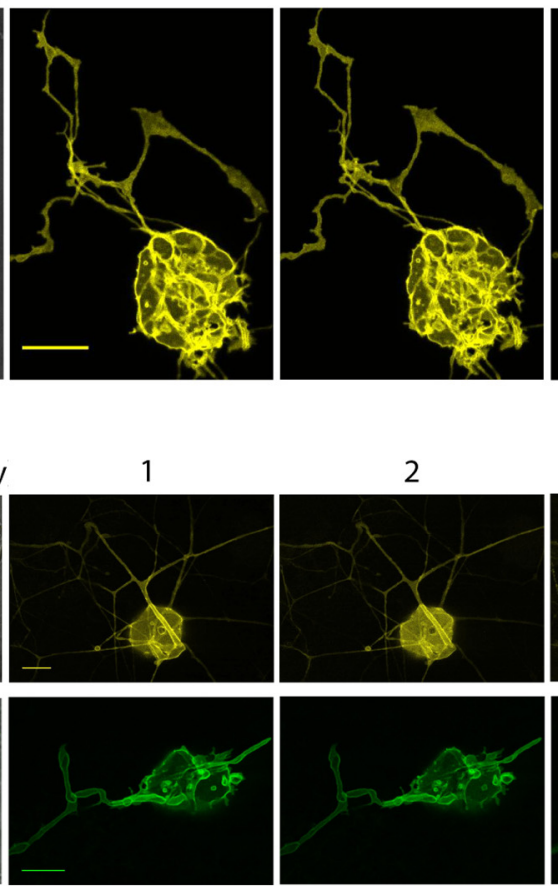

2

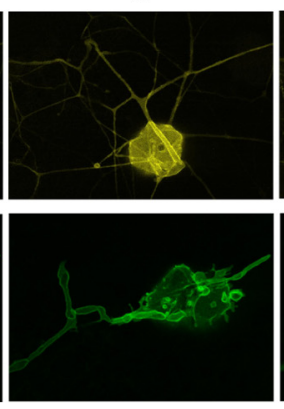

3

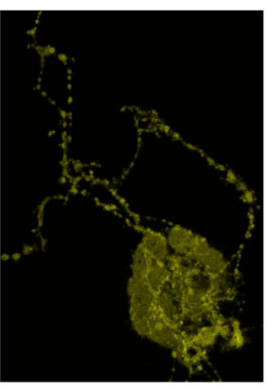

3

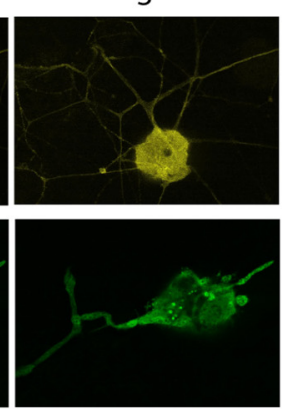

B
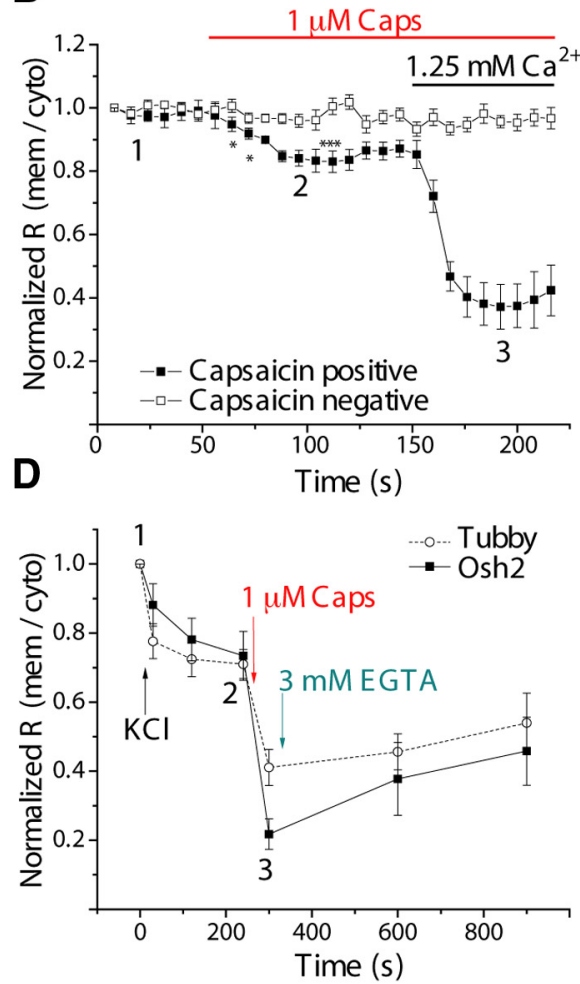

E

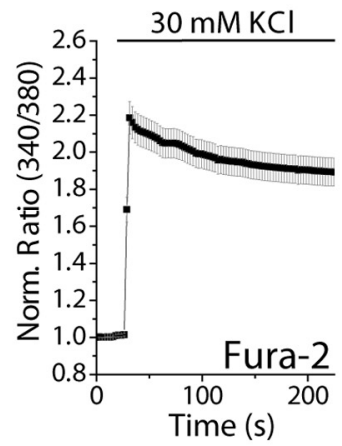

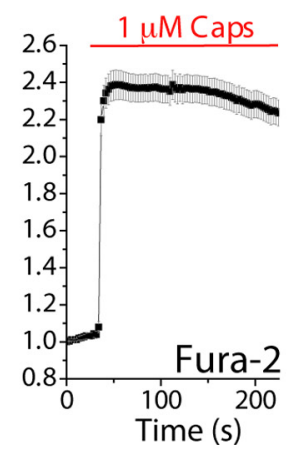

F

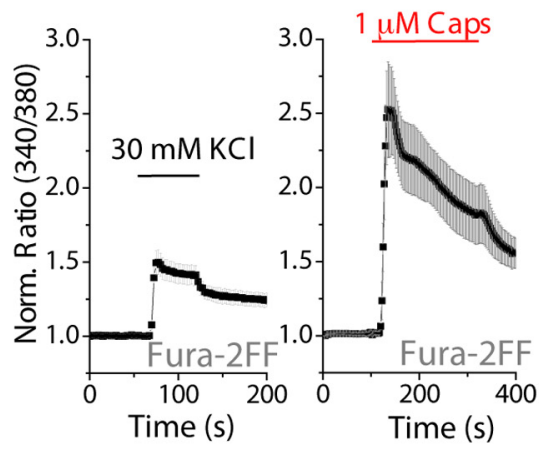

G

Fura-2 Fura-2FF

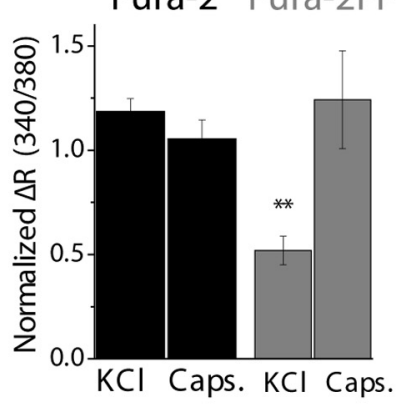

Figure 2. Breakdown of phosphoinositides is mediated by $\mathrm{Ca}^{2+}$ entry via TRPV1. $\boldsymbol{A}$, Confocal images in isolated DRG neurons expressing the YFP-tubby domain. Each of the three images represents a selected time point indicated by numbers $1-3$ from the time series measurement shown in $\boldsymbol{B}$. $\mathrm{Ca}^{2+}$ in the extracellular medium was initially chelated by adding $0.5 \mathrm{~mm}$ EGTA to the standard NCF solution, $\mathrm{Ca}^{2+}$ was then elevated to a $1.25 \mathrm{~mm}$ final concentration in the presence of $1 \mu$ m capsaicin $\left(n=5\right.$ or 6 neurons per group), ${ }^{*} p<0.05 .{ }^{* * *} p<0.005$. C, Representative images at time points indicated in $\boldsymbol{D}$ of neurons expressing either YFP-Tubby (top) or GFP-Osh2 (bottom) probes. Neurons were first depolarized with an isotonic solution containing 25 or $30 \mathrm{~mm}$ KCl and subsequently exposed to $1 \mu \mathrm{m}$ capsaicin (Caps). Results from 25 and $30 \mathrm{~mm} \mathrm{KCl}$ treatment were similar and were thus pooled for representation. Chelating extracellular $\mathrm{Ca}^{2+}$ with $3 \mathrm{~mm}$ EGTA induced partial relocalization of both probes to the plasma membrane. Data points represent mean \pm SEM of normalized fluorescence ratios of 7-10 TRPV1-positive cells. $E$, Representative mean \pm SEM normalized fluorescence ratios $\left(340 \mathrm{~nm} / 380 \mathrm{~nm}\right.$ ) from DRG neurons loaded with the ratiometric $\mathrm{Ca}^{2+}$ indicator fura-2 stimulated with either $30 \mathrm{~mm} \mathrm{KCl}$ or $1 \mu \mathrm{M}$ capsaicin (one coverslip each). $\boldsymbol{F}$, Representative fluorescence ratio changes $(340 \mathrm{~nm} / 380 \mathrm{~nm})$ from DRG neurons loaded with the low-affinity ratiometric $\mathrm{Ca}^{2+}$ indicator fura-2 FF. Experiments were conducted similarly to $E$; representative traces show measurements from one coverslip each. G, Bar graph represents statistics of $n=17$ or 18 capsaicin-positive cells from 3 coverslips in each group for fura- $2 \mathrm{FF}$ and $n=$ $39-43$ cells from 3 or 4 coverslips in each group for fura-2. Peak ratio changes are displayed as mean $\pm S E M$. ${ }^{* *} p<0.01$.

that both PI(4,5) $\mathrm{P}_{2}$ and $\mathrm{PI}(4) \mathrm{P}$ can maintain TRPV1 activity in excised patches (Lukacs et al., 2007).

Among the classical PLC isoforms, PLC $\delta$ s are the most $\mathrm{Ca}^{2+}$ sensitive, and they were shown to be activated by increased cytoplasmic $\mathrm{Ca}^{2+}$ alone (Rebecchi and Pentyala, 2000). Among the newer PLC isoforms, PLC $\eta$ are also quite $\mathrm{Ca}^{2+}$-sensitive (Cockcroft, 2006). We tested the expression levels of PLC $\delta$ and PLC $\eta$ isoforms in murine DRG with qRT-PCR. Figure $3 H$ shows that PLC 84 mRNA is dominant among these isoforms.

We therefore measured TRPV1 desensitization in PLC $84^{-1-}$ animals using the perforated patch technique (Fig. $3 D-F$ ), which allows measurement of current desensitization without disrup- tion of cytosolic contents. By the end of the first $1 \mathrm{~min}$ application of capsaicin, the currents in the PLC $\delta 4^{-1-}$ neurons were significantly larger than in control, consistent with reduced acute desensitization. In the beginning of the second application of capsaicin, there was a nonsignificant trend to have larger currents in the PLC 84 knock-out cells; this difference became significant by the end of the second application (Fig. 3D-F).

We also compared capsaicin-induced nerve impulses in wildtype and PLC $84^{-1-}$ animals using extracellular recordings from single C-fibers in the skin-nerve preparation (Fig. 3G). We measured nerve activity in response to two consecutive 4 min applications of $10 \mu \mathrm{M}$ capsaicin, separated by a $30 \mathrm{~min}$ wash period. In 
A

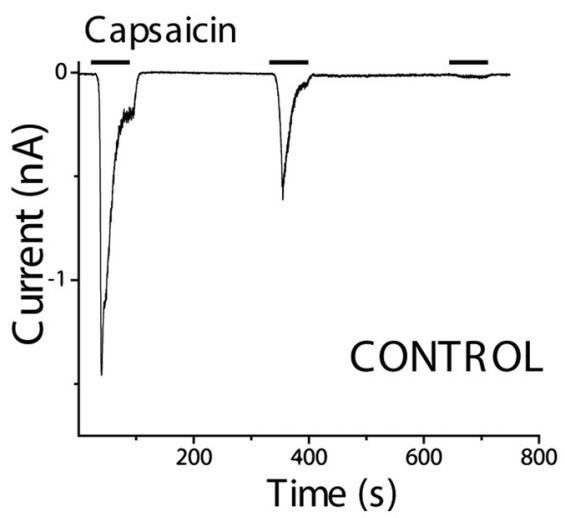

D

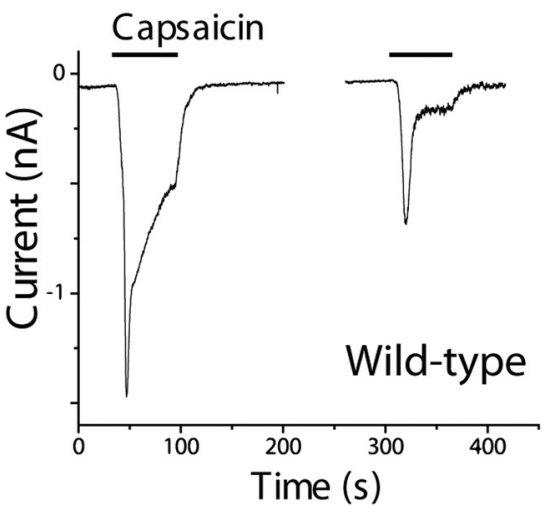

G

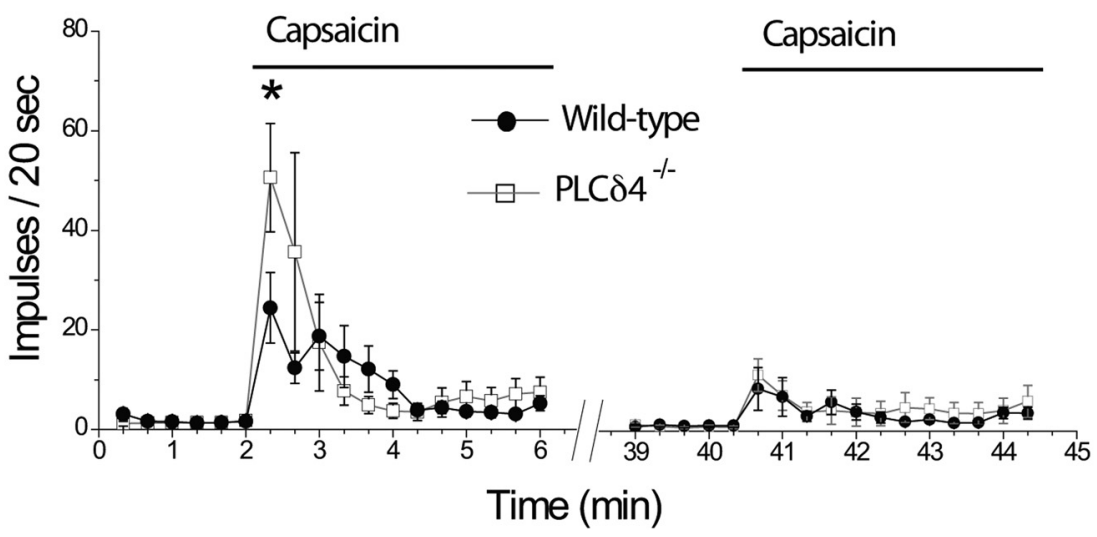

E
C
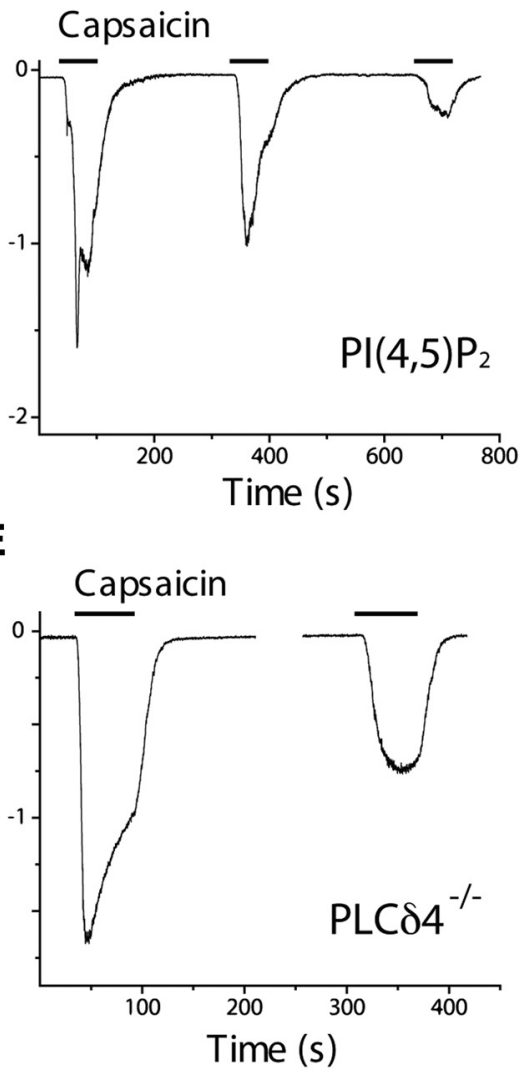

F

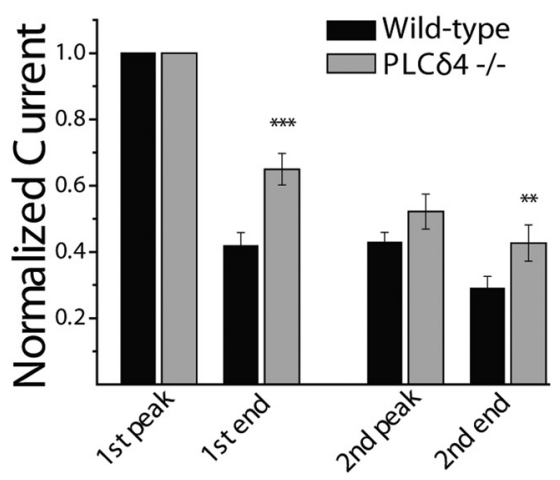

H

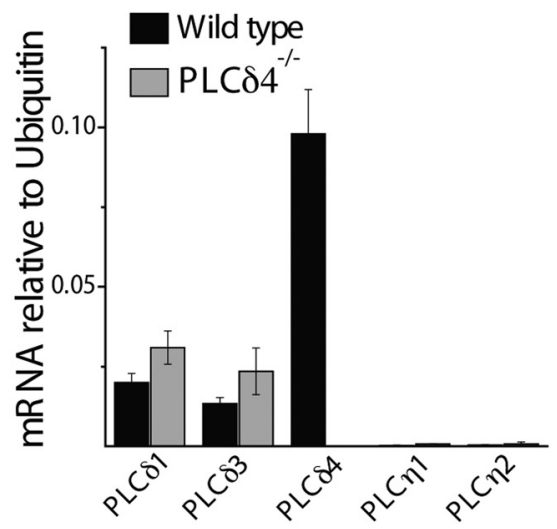

Figure 3. Inhibiting PI(4)P or PI(4,5)P 2 depletion reduces TRPV1 desensitization in neurons. $A, B$, Representative whole-cell voltage-clamp traces of inward currents recorded at $-60 \mathrm{mV}$ from isolated DRG neurons. Measurements were conducted in standard NCF solution supplemented with $1.25 \mathrm{~mm} \mathrm{CaCl}$. Before each measurement, a waiting period of 2-3 min was used in the whole-cell setting to allow for diffusion of the pipette solutions, which were based on NIC-DRG (see Materials and Methods) and supplemented as follows: control, no lipid supplement $(\boldsymbol{A}), 100 \mu \mathrm{m} \mathrm{diC}{ }_{8}-\mathrm{PI}(4,5) \mathrm{P}_{2}(\boldsymbol{B})$, and $100 \mu \mathrm{m} \mathrm{diC} \mathrm{C}_{8}-\mathrm{PI}(4) \mathrm{P}$ (representative trace not shown). C, Statistical analysis of $n=6-8$ neurons in each group (control, $\mathrm{diC}_{8}-\mathrm{PI}(4,5) \mathrm{P}_{2}$ and DiC $-\mathrm{PI}(4) \mathrm{P}$, respectively) displayed as mean $\pm \mathrm{SEM}$. Current values were normalized to the peak of the first current response and measured subsequently at the peak and end of each capsaicin pulse. There were no statistically significant differences in the raw current densities between the three groups (ANOVA: $124 \pm 26 \mathrm{pA} / \mathrm{pF}$ for control, $94 \pm 29 \mathrm{pA} / \mathrm{pF}$ for PI(4,5) $\mathrm{P}_{2}$, and $81 \pm 30 \mathrm{pA} / \mathrm{pF}$ for PI(4)P groups, respectively). ${ }^{*} p<0.05$. $\boldsymbol{D}-\boldsymbol{F}$, Perforated patch-clamp experiments on DRG neurons. Representative traces of $P L C \delta 4^{-I-}(\boldsymbol{E})$ and wild-type littermate controls $(\boldsymbol{D})$. To ensure fidelity of the measurements of large currents evoked by $1 \mu \mathrm{m}$ capsaicin recordings were interrupted between stimulus pulses to check for stability of low access resistance of the perforated patch (see Materials and Methods). $\boldsymbol{F}$, Statistical analysis of current amplitudes normalized to the first peak. Bars represent mean \pm SEM of $n=15 P L C \delta 4^{-1-}$ and $n=22$ wild-type control measurements. There was no significant difference between the raw current densities recorded from neurons of knock-out and control animals. ${ }^{* *} p<0.01$. ${ }_{* * *}^{*}<0.005$. G, Extracellular single-fiber recordings in the skin-nerve preparation were performed as described in Materials and Methods. After a 2 min control recording, the receptive field was stimulated for 4 min with $10 \mu$ m capsaicin, followed by a 30 min wash period, then a second 4 min application of $10 \mu$ capsaicin. Nerve impulses were divided into $20 \mathrm{~s}$ bins and plotted; $n=29$ for $P L C \delta 4^{-1-}$ and $n=32$ for wild-type littermates. $\boldsymbol{H}$, Real-time PCR analysis of highly calcium-sensitive PLC isoform expression in crude DRG mRNA extracts of wild-type or PLC $\delta 4$ KO mice. Bars represent mean \pm SEM of relative mRNA quantities, calculated from five separate isolations (control) or two separate isolations (KO) as normalized to ubiquitin-a mRNA levels.

both groups, capsaicin induced a robust nerve discharge that decreased over time despite the continuous presence of capsaicin. Capsaicin-induced nerve activity was significantly higher in the $P L C \delta 4^{-1-}$ animals than in wild-type in the first $20 \mathrm{~s}$ bin and substantially higher in the second $20 \mathrm{~s}$ bin, but the difference did not reach statistical significance. No significant difference was observed in the next $3 \mathrm{~min}$. The second application of capsaicin induced a much smaller effect on nerve activity, consistent with 
A
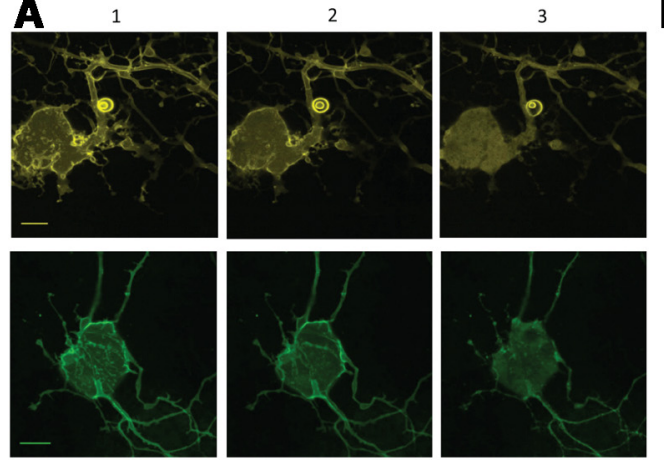

Figure 4. Bradykinin decreases $\mathrm{PI}(4,5) \mathrm{P}_{2}$, but not $\mathrm{PI}(4) \mathrm{P}$, levels in DRG neurons. $\boldsymbol{A}$, Representative images of isolated DRG neurons transfected either with the YFP-tagged R332H Tubby domain (top) or the GFP-tagged Osh2-tandem-PH domain construct (bottom). Images in each of the three columns represent time points in $\boldsymbol{B}$ indicated by $1-3$. $\boldsymbol{B}$, Mean \pm SEM of normalized membrane to cytoplasm fluorescence ratios recorded from $n=7-10$ neurons. The measurements were conducted in standard NCF solution supplemented with $1.25 \mathrm{~mm} \mathrm{CaCl}$. Scale bars, $10 \mu \mathrm{m}$.

desensitization. There was no significant difference between wild-type and $P L C \delta 4^{-1-}$ animals during the second application, even though there was a slight trend to have higher activity in the knock-out animals in the later phase. Overall, the higher capsaicin-induced nerve activity in the PLC $\delta 4^{-/-}$animals at the beginning of the first application of capsaicin is broadly consistent with our model, considering that, in patch-clamp experiments, the most robust difference was observed during the first 1 min application of capsaicin. The temporal correlation between the two assays was not perfect, but we have to keep in mind that nerve activity is a lot more complex phenomenon than currents measured in patch-clamp experiments.

Consistent with the relatively moderate phenotype of the genetic deletion of PLC $\delta 4$, there was a slight trend to upregulate PLC $\delta 1$ and PLC $\delta 3$ on the mRNA level in the knock-out animals (Fig. $3 H$ ). We also measured capsaicin-induced translocation of the tubby $\mathrm{PI}(4,5) \mathrm{P}_{2}$ probe in DRG neurons isolated from PLC $\delta 4^{-I-}$ animals. The YFP-tubby probe completely disappeared from the plasma membrane, similar to wild-type neurons (data not shown). This indicates that other PLC isoforms are still capable of significant $\mathrm{PI}(4,5) \mathrm{P}_{2}$ depletion, and it is likely that the capability to detect a difference from wild-type is outside the dynamic range of this assay. The affinity of TRPV1 for $\mathrm{PI}(4,5) \mathrm{P}_{2}$, however, is very high (Lukacs et al., 2007; Klein et al., 2008); thus, at low $\mathrm{PI}(4,5) \mathrm{P}_{2}$ levels, even small differences in the concentration of the lipid can affect channel activity.

\section{Bradykinin induces a selective decrease of $\mathrm{PI}(4,5) \mathrm{P}_{2}$ levels contributing to TRPV1 sensitization}

Bradykinin is a key inflammatory mediator that has been shown to sensitize TRPV1 through $\mathrm{B}_{2}$ receptors, which couple to PLC activation (Cesare et al., 1999; Chuang et al., 2001). Figure 4 shows that bradykinin induced a moderate decrease in plasma membrane $\mathrm{PI}(4,5) \mathrm{P}_{2}$ levels as reported by the fluorescent Tubby domain (Fig. 4B). The localization of the PI(4)P indicator Osh2, on the other hand, was altered only transiently, returning to baseline within the first minute of receptor activation and remaining unchanged despite the continued presence of bradykinin for several minutes (Fig. 4B). This represents a clear difference in phosphoinositide handling between bradykinin receptor-mediated PLC activation and that induced by $\mathrm{Ca}^{2+}$ influx through TRPV1 shown in Figures 1 and 2.

When interpreting these data, one important point needs to be considered. Even though the Osh2 tandem-PH domain re- mains the best available tool to date for detection of $\mathrm{PI}(4) \mathrm{P}$ levels, it has been shown that it also binds $\mathrm{PI}(4,5) \mathrm{P}_{2}$ in vitro (Roy and Levine, 2004). It was clearly shown, however, that isolated complete $\mathrm{PI}(4,5) \mathrm{P}_{2}$ depletion does not lead to its translocation to the cytoplasm, whereas combined decrease in $\mathrm{PI}(4) \mathrm{P}$ and $\mathrm{PI}(4,5) \mathrm{P}_{2}$ does (Balla et al., 2008; Hammond et al., 2012). Thus, this probe may also be considered a combined PI(4)P and $\mathrm{PI}(4,5) \mathrm{P}_{2}$ sensor. The combined use of the Osh2 probe with the specific $\mathrm{PI}(4,5) \mathrm{P}_{2}$ probe tubby grants the capability to make inferences as to the changes in PI(4)P levels. Treatment of DRG neurons with capsaicin induced an essentially complete translocation of both the tubby and the Osh2 $\mathrm{PH}$ domains, indicating a robust decrease of both $\mathrm{PI}(4) \mathrm{P}$ and $\mathrm{PI}(4,5) \mathrm{P}_{2}$ levels (Figs. 1, 2, and $4)$. Bradykinin treatment, on the other hand, induced translocation of the $\mathrm{PI}(4,5) \mathrm{P}_{2}$ sensor tubby domain and no movement of the Osh2 probe (Fig. 4). We interpret this as no, or negligible, change in $\mathrm{PI}(4) \mathrm{P}$ levels in response to bradykinin. Because $\mathrm{PI}(4,5) \mathrm{P}_{2}$ levels clearly decrease in response to bradykinin, if there was a significant change in $\mathrm{PI}(4) \mathrm{P}$ levels, the Osh2 probe would be expected to translocate as well. Our finding, that upon $\mathrm{KCl}$ treatment a similar, moderate translocation of the tubby probe was indeed accompanied by a parallel translocation of the Osh2 probe (Fig. 2), gives support to this idea. Our data show that capsaicin treatment results in a robust decrease in both $\mathrm{PI}(4,5) \mathrm{P}_{2}$ and $\mathrm{PI}(4) \mathrm{P}$ levels in isolated sensory neurons, whereas GPCR activation by bradykinin causes a moderate reduction in $\mathrm{PI}(4,5) \mathrm{P}_{2}$ abundance and no, or negligible, long-lasting change in PI(4)P levels.

We next asked whether selective reduction in $\mathrm{PI}(4,5) \mathrm{P}_{2}$ levels is involved in TRPV1 sensitization by bradykinin based on the inhibitory effect of $\mathrm{PI}(4,5) \mathrm{P}_{2}$ (Chuang et al., 2001; Lukacs et al., 2007; Cao et al., 2013). Figure 5 shows that dialysis of $\mathrm{diC}_{8^{-}}$ $\mathrm{PI}(4,5) \mathrm{P}_{2}$ through the patch pipette strongly decreased bradykinin-induced sensitization of native TRPV1 currents in DRG neurons (Fig. $5 B, D$ ), whereas diC $_{8}-\mathrm{PI}(4) \mathrm{P}$ at identical concentrations had no effect (Fig. 5C,D).

In 5 of 32 DRG neurons, bradykinin also induced an inward current (Fig. 5C). It was reported previously that bradykinin induces a $\mathrm{Ca}^{2+}$-induced $\mathrm{Cl}^{-}$current in these cells, which is mediated by the TMEM16A ion channel (Liu et al., 2010). These measurements were performed using a low intracellular $\mathrm{Cl}^{-}$solution (see Materials and Methods), with the calculated $\mathrm{Cl}^{-}$equilibrium potential close to the $-60 \mathrm{mV}$ holding, which argues against the current being the $\mathrm{Ca}^{2+}$-activated $\mathrm{Cl}^{-}$current. The actual equilibrium potential of $\mathrm{Cl}^{-}$in our whole-cell experiments is difficult to predict, however, because of the cell's own exchange mechanisms and the likely variable intracellular exchange between the pipette and the cell. Thus, it cannot be excluded that this current corresponds to $\mathrm{Ca}^{2+}$-activated $\mathrm{Cl}^{-}$ channels.

These measurements were performed in the presence of 1.25 mu extracellular $\mathrm{Ca}^{2+}$, whereas intracellular $\mathrm{Ca}^{2+}$ was buffered weakly to $100 \mathrm{~nm}$ (see Materials and Methods). We used these physiologically relevant conditions to increase external validity of our findings because sensitization is usually tested in $\mathrm{Ca}^{2+}$-free conditions to prevent concurrent desensitization. This result was 
A

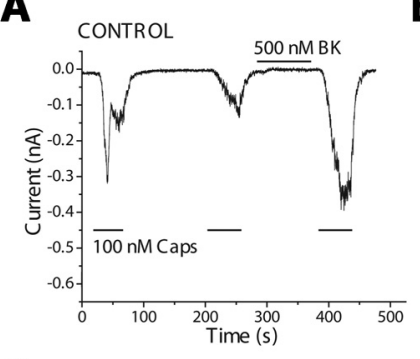

$\mathbf{B}$

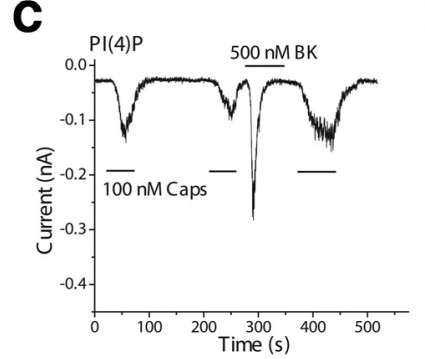

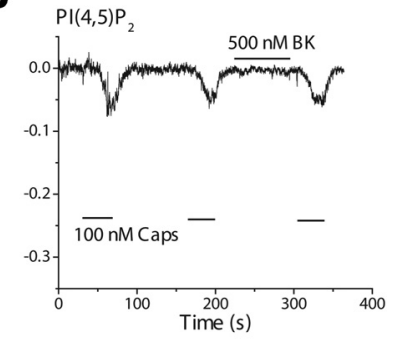

D

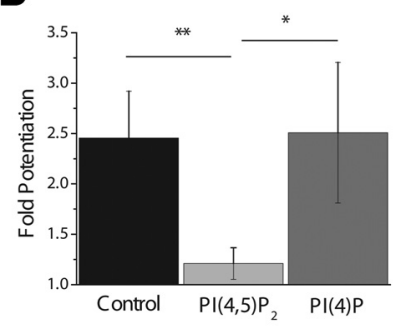

Figure 5. Intracellular dialysis of $\mathrm{PI}(4,5) \mathrm{P}_{2}$, but not $\mathrm{PI}(4) \mathrm{P}$, inhibits sensitization of capsaicininduced currents by bradykinin in DRG neurons. $A-C$, Whole-cell current recordings from isolated DRG neurons clamped at $-60 \mathrm{mV}$ in standard NCF solution supplemented with $1.25 \mathrm{~mm}$ $\mathrm{Ca}^{2+}$, demonstrating the effect of dialysis of intracellular solutions based on NIC-DRG and supplemented as follows: $\boldsymbol{A}$, Control, no supplement $(n=12) ; \boldsymbol{B}, 100 \mu \mathrm{M} \mathrm{diC}{ }_{8}-\mathrm{PI}(4,5) \mathrm{P}_{2}(n=$ 10); $C, 100 \mu \mathrm{M} \mathrm{diC}_{8}-\mathrm{PI}(4) \mathrm{P}(n=10)$. $\boldsymbol{D}$, Summary represented as mean \pm SEM of fold increase in current as calculated by the ratio of $100 \mathrm{~nm}$ capsaicin responses immediately before and after the 1 min application of bradykinin. ${ }^{*} p<0.05,{ }^{* *} p<0.01$. Statistical analysis was performed with the Student's t test. There were no statistically significant differences between raw current densities in the three groups.

also reproducible under the commonly used high intracellular and extracellular calcium buffering in HEK293 cells coexpressing TRPV1 and the bradykinin B2 receptor. Potentiation of responses to either moderately low $\mathrm{pH}$ (Fig. $6 A-D$ ) or submaximal capsaicin stimuli (Fig. $6 D$ ) were similarly strongly inhibited by $\mathrm{PI}(4,5) \mathrm{P}_{2}$ dialysis. In addition to $\mathrm{PI}(4,5) \mathrm{P}_{2}$, the highly $\mathrm{PKC}$ specific pseudo-substrate inhibitor 19-31 amide also impaired TRPV1 sensitization (Fig. 6C,D), confirming the well-established role of $\mathrm{PKC}$ in this phenomenon.

\section{A decrease in both $\mathrm{PI}(4) \mathrm{P}$ and $\mathrm{PI}(4,5) \mathrm{P}_{2}$, but not $\mathrm{PI}(4,5) \mathrm{P}_{2}$ alone, inhibits TRPV1}

Our data so far suggest that differential changes in phosphoinositides are involved in opposite TRPV1 regulation during capsaicin-induced channel desensitization and proinflammatory channel sensitization. To further establish this point, we attempted to experimentally recapitulate the changes in phosphoinositide levels we observed in the two different conditions independently of PLC activation to determine whether they would mimic the changes in TRPV1 sensitivity. Capsaicininduced and low pH-evoked TRPV1 currents generally behaved similarly in our hands in terms of channel sensitization; we therefore used the more physiological extracellular acidification in the following experiments in HEK293 cells. Unlike neurons, the endogenous acid-evoked currents in these cells were negligible compared with TRPV1-mediated responses (data not shown).

We used the zebrafish voltage-sensitive phosphoinositide phosphatase (Dr-VSP) in whole-cell voltage-clamp measurements in HEK293 cells to induce selective conversion of $\mathrm{PI}(4,5) \mathrm{P}_{2}$ to PI(4)P (Hossain et al., 2008). Depolarization activates this phosphatase, which induces dephosphorylation of $\mathrm{PI}(4,5) \mathrm{P}_{2}$ at the $5^{\prime}$ position, resulting in $\mathrm{PI}(4) \mathrm{P}$ production (Murata et al.,
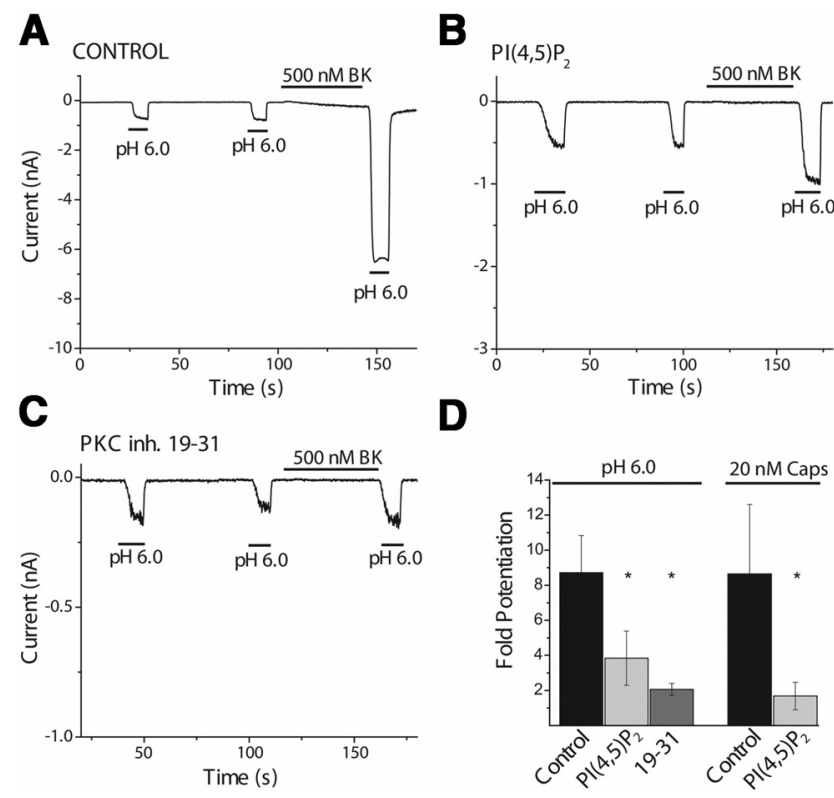

D

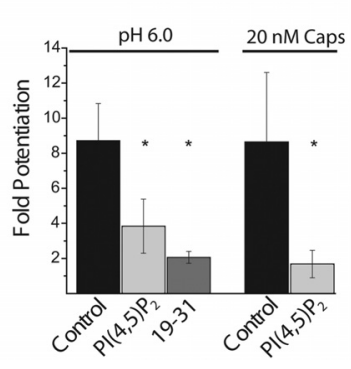

Figure 6. Intracellular dialysis of $\mathrm{PI}(4,5) \mathrm{P}_{2}$ inhibits sensitization of low $\mathrm{pH}$-induced TRPV1 currents. Whole-cell current recordings at $-60 \mathrm{mV}$ from HEK 293 cells coexpressing TRPV1 and the bradykinin B2 receptor. The bath solution was standard NCF supplemented with 5 mм EGTA to prevent desensitization. Traces representative of the effects of intracellular diffusion of standard NIC solution supplemented with the following: $\boldsymbol{A}$, control, no substitution $(n=14) ; \boldsymbol{B}, 100$ $\mu \mathrm{M} \mathrm{diC}_{8}-\mathrm{PI}(4,5) \mathrm{P}_{2}(n=15) ; C, 2 \mu \mathrm{m} 19-31$ amide PKC inhibitor peptide $(n=11)$. D, Summary of results obtained by stimulation of TRPV1 with low extracellular pH (left) or $20 \mathrm{~nm}$ capsaicin (right; $n=11$ control and $n=8 \mathrm{PI}(4,5) \mathrm{P}_{2}$ ). Sensitization was calculated as the ratio of current amplitudes evoked by low pH or capsaicin pulses immediately before and after bradykinin application. Bars represent mean \pm SEM for each group. * $p<0.05$ (Mann-Whitney $U$ test). There were no statistically significant differences in initial raw current amplitudes between the various groups.

2005; Suh et al., 2010). We found that Dr-VSP activation had no effect on TRPV1 currents (Fig. 7 A,C) despite the fact that a robust decrease in $\mathrm{PI}(4,5) \mathrm{P}_{2}$ levels was evidenced in these cells by complete inhibition of Kir2.1 (Fig. $7 A, D$ ), a channel well known to display high selectivity and high apparent affinity for $\mathrm{PI}(4,5) \mathrm{P}_{2}$ (Rohacs et al., 1999; Du et al., 2004). Given the high apparent affinity of Kir2.1 for $\mathrm{PI}(4,5) \mathrm{P}_{2}$, its inhibition requires a substantial decrease in $\mathrm{PI}(4,5) \mathrm{P}_{2}$ levels ( $\mathrm{Du}$ et al., 2004). The phosphatase-inactive negative control mutant Dr-VSP had no effect on either channel (Fig. $7 B-D$ ). The lack of inhibition of TRPV1 by selective conversion of $\mathrm{PI}(4,5) \mathrm{P}_{2}$ to $\mathrm{PI}(4) \mathrm{P}$ argues in favor of the ability of PI(4)P to support channel activity.

It is also possible that D-VSP had no access to the plasma membrane pool of $\mathrm{PI}(4,5) \mathrm{P}_{2}$ associated with TRPV1. This is not very likely, however, because a large number of wellcharacterized $\mathrm{PI}(4,5) \mathrm{P}_{2}$ dependent ion channels have been shown to be robustly inhibited by this enzyme or its relative C-VSP upon depolarization (Hossain et al., 2008; Suh et al., 2010; Yudin et al., 2011). Similar to D-VSP, we could not detect any inhibition of TRPV1 currents using C-VSP (data not shown).

We then attempted to simultaneously deplete both lipids, similarly to that seen during treatment with high concentrations of capsaicin. We achieved this by the recently described rapamycin-inducible rapid dephosphorylation system Pseudojanin, a fusion protein that contains both the $4^{\prime}$-phosphatase domain of the protein Sacl and a constitutively active 5'phosphatase (Hammond et al., 2012). Rapamycin application induces translocation of the phosphatase to the plasma membrane resulting in depletion of both $\mathrm{PI}(4) \mathrm{P}$ and $\mathrm{PI}(4,5) \mathrm{P}_{2}$. As 
A
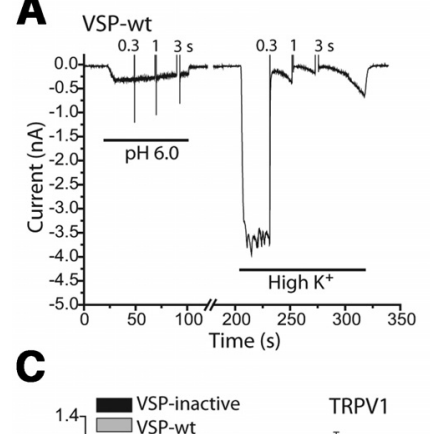

B

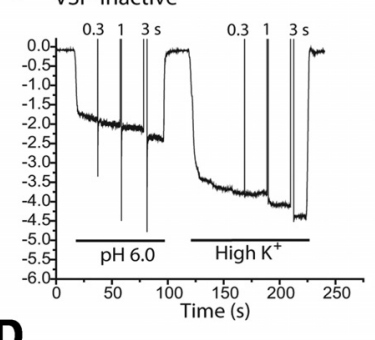

D
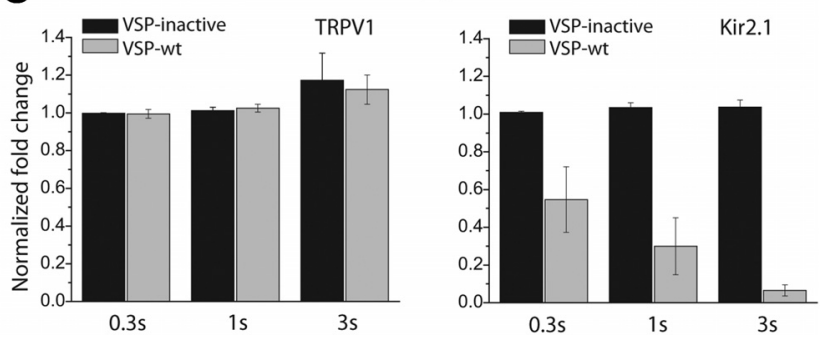

Figure 7. Selective conversion of $\mathrm{PI}(4,5) \mathrm{P}_{2}$ to $\mathrm{PI}(4) \mathrm{P}$ has no effect on TRPV1 currents. $\boldsymbol{A}, \boldsymbol{B}$, Representative whole-cell voltage-clamp traces from HEK293 cells transiently cotransfected with TRPV1, Kir2.1, and either the wild-type (wt) or the catalytically inactive voltage-sensitive phosphatase from zebrafish (Dr-VSP). Standard NCF solution was supplemented with $5 \mathrm{~mm}$ EGTA to prevent desensitization of the channel. Intracellular solution was Cs-IC (see Materials and Methods). TRPV1 currents were activated by low pH, whereas inward potassium currents through Kir2.1 were initiated by elevating the extracellular potassium concentration to $100 \mathrm{~mm}$ (high $\mathrm{K}^{+}$, osmolarity maintained) while maintaining a holding potential of $-60 \mathrm{mV}$. Successive depolarizing steps of $0.3,1$, and $3 \mathrm{~s}$ to $+100 \mathrm{mV}$ were used to activate the VSP. This was repeated both while measuring TRPV1 and Kir2.1 currents. $C$, D, Summary statistics of the effect of VSP activation on TRPV1 $(\boldsymbol{C})$ and Kir2.1 (D) currents. Statistics shown represent $n=6$ cells in the VSP-inactive group and $n=11$ in the VSP-wt group. Data are mean \pm SEM are shown.

shown in Figure 8B, $D$ (also see $\mathrm{pH} 6$ response magnified in Fig. $8 C$ ), TRPV1 activity in response to both submaximal and maximal stimuli was significantly inhibited by application of rapamycin. Rapamycin induced no change in TRPV1 currents at either stimulation levels in the negative control group with an inactive phosphatase (Fig. $8 A, C, D$ ).

As a complementary approach, we tested the effect of inhibition of PI4-kinases in oocytes with a high $(35 \mu \mathrm{M})$ concentration of wortmannin, often used to reduce $\mathrm{PI}(4,5) \mathrm{P}_{2}$ levels to study $\mathrm{PI}(4,5) \mathrm{P}_{2}$-sensitive ion channels (Zhang et al., 2003; Rohacs et al., 2005). At this concentration, this compound inhibits type III PI4-kinases as well as PI3-kinases (Balla, 2001); however, because of the minimal resting activity of the latter, the expected effect of this treatment is predominantly via inhibition of PI4-kinases. As a negative control, we used $35 \mathrm{~nm}$ of the drug where it specifically inhibits PI3-kinases. Because PI4K-kinases catalyze the formation of $\mathrm{PI}(4) \mathrm{P}$, a reduction in $\mathrm{PI}(4,5) \mathrm{P}_{2}$ levels is only possible if $\mathrm{PI}(4) \mathrm{P}$ is also decreased. PI(4)P levels have indeed been shown to decrease in response to micromolar wortmannin treatment (Korzeniowski et al., 2009). We pretreated Xenopus oocytes expressing TRPV1 with this drug for $90 \mathrm{~min}$ and assessed TRPV1 responses to various stimulus intensities, comparing them with vehicle-treated controls. Figure $8 E$ shows that pretreatment with $35 \mu \mathrm{M}$ wortmannin inhibited TRPV1 responses, whereas $35 \mathrm{nM}$ had no effect. The inhibitory effect was more prevalent at submaximal $\mathrm{pH}$ stimuli, which is probably the result of the increased apparent affinity of TRPV1 for phosphoinositides at higher agonist concentrations, as demonstrated previously (Lukacs et al., 2007). Reduction of phosphoinositides by wortmannin pretreatment has been shown to result in only small or no inhibition of
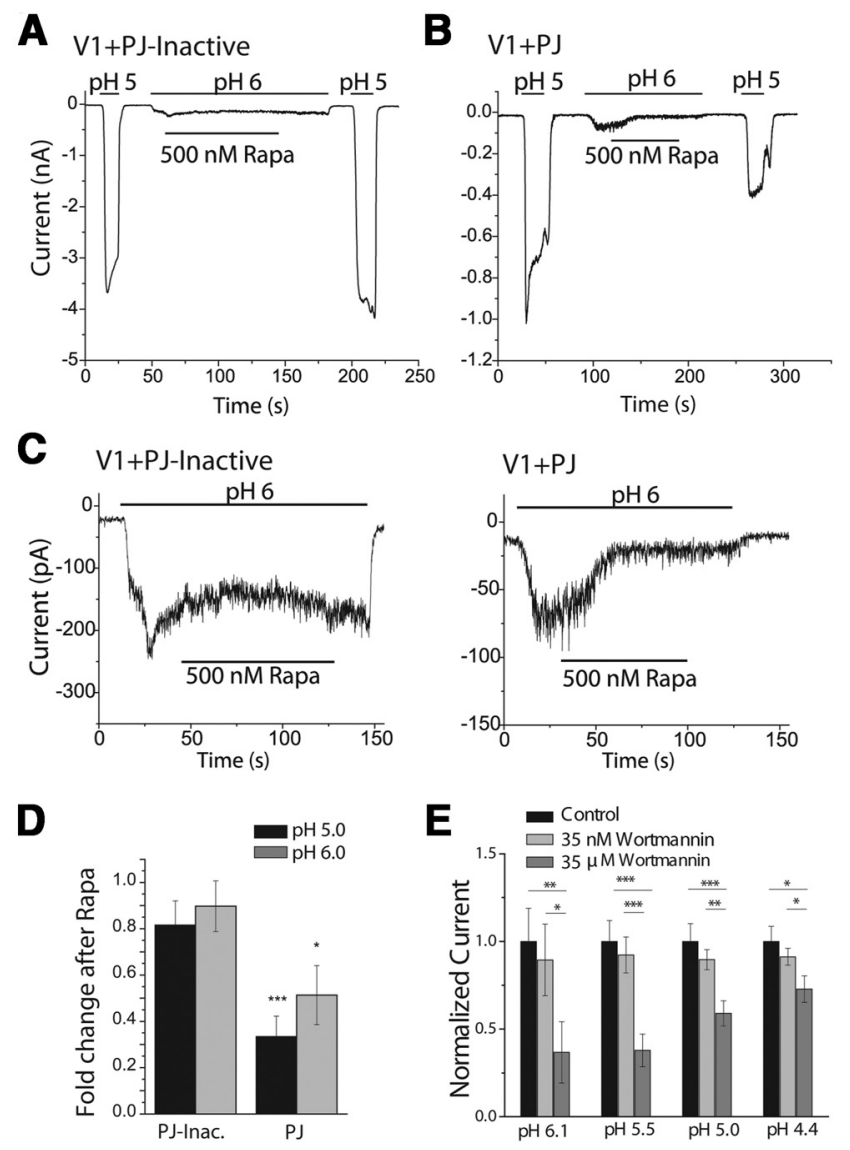

Figure 8. Simultaneous $\mathrm{PI}(4) \mathrm{P}$ and $\mathrm{PI}(4,5) \mathrm{P}_{2}$ decrease inhibits TRPV1. HEK293 cells coexpressing TRPV1 and either the rapamycin-inducible dual $4^{\prime}$ and $5^{\prime}$ phosphatase system Pseudojanin (PJ) or its catalytically inactive negative control pair (PJ-inactive) were voltage-clamped in the whole-cell configuration in standard NCF containing $5 \mathrm{~mm}$ EGTA added to prevent $\mathrm{Ca}^{2+}$ induced desensitization. Intracellular solution was NIC. $\boldsymbol{A}, \boldsymbol{B}$, Representative traces of inward TRPV1 currents at $-60 \mathrm{mV}$ demonstrating the protocol applied. C, Magnification of the pH 6.0 responses from the representative traces from $\boldsymbol{A}$ and $\boldsymbol{B}$. D, Summary (mean \pm SEM) of the effect of selective decrease of both $\mathrm{PI}(4) \mathrm{P}$ and $\mathrm{PI}(4,5) \mathrm{P}_{2} 1$ min after the start of $500 \mathrm{~nm}$ rapamycin perfusion. Fold changes were normalized to stable current values observed immediately before rapamycin application $(n=6$ or 7$) .{ }^{*} p<0.05,{ }^{* * *} p<0.005$. E, Two-electrode voltage-clamp recording from Xenopus laevis 0ocytes heterologously expressing TRPV1 channels (see Materials and Methods). The effect of a 90 min pretreatment with either $35 \mu \mathrm{m}$ or $35 \mathrm{~nm}$ wortmannin on current responses to the indicated $\mathrm{pH}$ challenges are shown normalized to the average values observed in the control (DMSO-treated) group. Data are plotted as mean \pm SEM of $n=21$ in the control group and 26 in both the $35 \mu \mathrm{m}$ and $35 \mathrm{~nm}$ wortmannin-treated groups. ${ }^{*} p<0.05$, ${ }^{* *} p<0.01,{ }^{* * *} p<0.005$.

$\mathrm{PI}(4,5) \mathrm{P}_{2}$-dependent channels with a higher apparent affinity for the lipid (Zhang et al., 2003; Rohacs et al., 2005).

\section{Selective decrease in $\mathrm{PI}(4,5) \mathrm{P}_{2}$ levels potentiates TRPV1 through PKC}

PLC-coupled GPCR activation results in PKC activation as well as a selective decrease in $\mathrm{PI}(4,5) \mathrm{P}_{2}$ levels. We therefore examined whether selective decrease in $\mathrm{PI}(4,5) \mathrm{P}_{2}$ levels is able to enhance the sensitizing effect of PKC activation. We used HEK293 cells coexpressing TRPV1, Kir2.1, and either the active or an inactive Dr-VSP (Hossain et al., 2008). In whole-cell voltage-clamp experiments, we first recorded control TRPV1 responses to submaximal $\mathrm{pH}$ stimuli and then depolarized the cells inducing maximal inhibition of Kir2.1. We then applied the PKC activator OAG at a subthreshold concentration and measured TRPV1 responses (Fig. 9). OAG at $1 \mu \mathrm{M}$ had no significant potentiating 
A

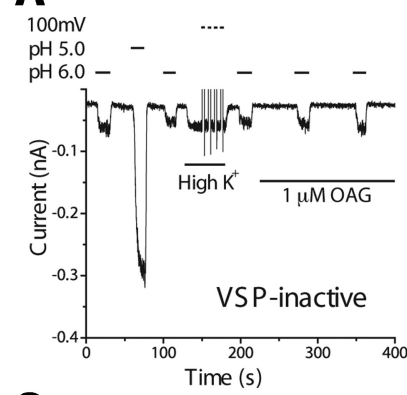

C

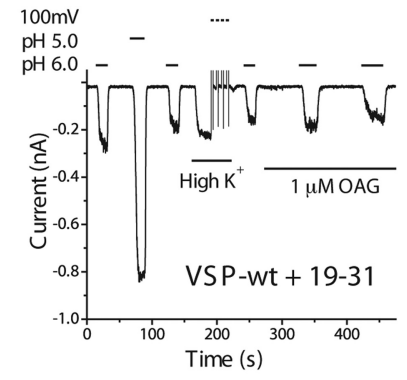

\section{E}

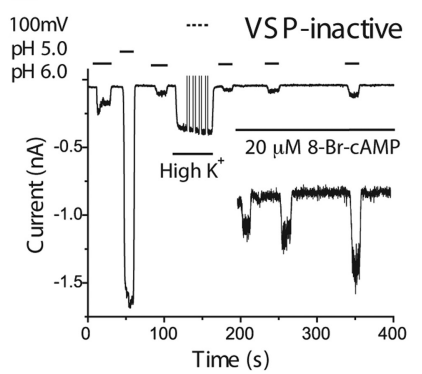

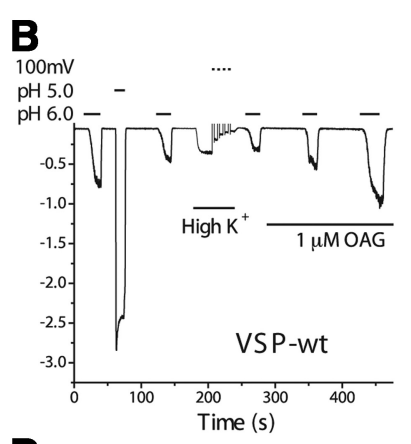

D
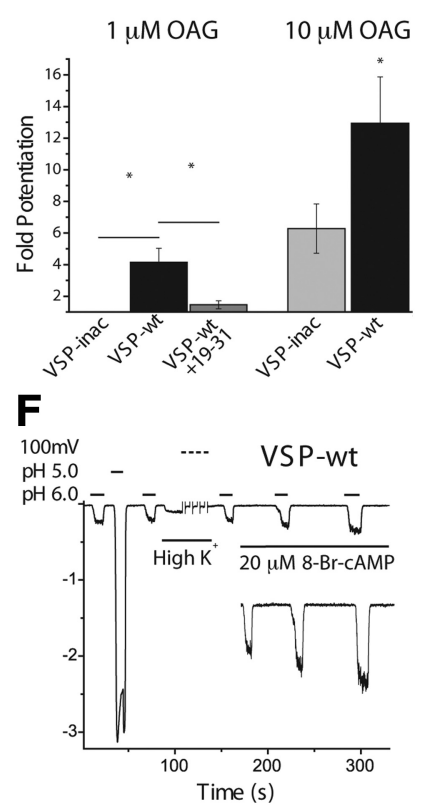

Figure 9. Selective conversion of $\mathrm{PI}(4,5) \mathrm{P}_{2}$ to $\mathrm{PI}(4) \mathrm{P}$ synergizes with $\mathrm{PKC}$-mediated, but not with PKA-mediated, phosphorylation to sensitize TRPV1. $\boldsymbol{A}$-C, Representative whole-cell current traces in HEK293 cells at $-60 \mathrm{mV}$ coexpressing TRPV1, Kir2.1, and either a catalytically active (wt) or inactive Dr-VSP. Currents were measured in standard NCF solution supplemented with $5 \mathrm{~mm}$ EGTA to prevent $\mathrm{Ca}^{2+}$-induced desensitization. After establishment of baseline TRPV1 currents, successive $3 \mathrm{~s}$ depolarizing pulses to $+100 \mathrm{mV}$ were applied to elicit maximal conversion of $\mathrm{PI}(4,5) \mathrm{P}_{2}$ to $\mathrm{PI}(4) \mathrm{P}$. This was performed in the presence of $100 \mathrm{~mm}$ extracellular $\mathrm{K}^{+}\left(\right.$High $\left.\mathrm{K}^{+}\right)$to assess the effect of $\mathrm{PI}(4,5) \mathrm{P}_{2}$ depletion on Kir2.1 channels. Then, after a final control pH 6.0 pulse, the PKC activator OAG was applied at either 1 or $10 \mu \mathrm{m}$ concentration, and the effects were assessed on $\mathrm{pH}$ 6.0-elicited TRPV1 responses. The intracellular solutions were based on Cs-IC (see Materials and Methods) and complemented as follows: $\boldsymbol{A}, \boldsymbol{B}$, no addition; $\boldsymbol{C}$, 19-31 amide PKC inhibitor peptide $(2 \mu \mathrm{M})$. D, Summary of findings as represented by mean \pm SEM of 5 or 6 traces in each group. Fold potentiation was calculated by dividing the amplitude of the second low $\mathrm{pH}$ pulse after $0 A \mathrm{G}$ with that preceding the application of OAG. This value was $0.965 \pm 0.12$ for the inactive VSP with $1 \mu \mathrm{m} 0$ AG. ${ }^{*} p<0.05$ (Student's $t$ test). $\boldsymbol{E}, \boldsymbol{F}$, Representative whole-cell current traces in HEK293 cells at $-60 \mathrm{mV}$ coexpressing TRPV1, Kir2.1, and either the wild-type or inactive Dr-VSP. PKA was activated by the cell-permeable 8-Br-cAMP (20 $\mu \mathrm{M})$, and its effect on $n=8$ cells in both groups was quantified as the ratio of TRPV1 current responses before and after PKA activation. TRPV1 sensitization was $1.57 \pm 0.315$-fold and $1.504 \pm 0.309$-fold in the VSP-inactive and VSP-wt groups, respectively. Insets, The last $3 \mathrm{pH}$ pulses on an enlarged scale.

effect on TRPV1 in cells expressing the phosphatase-inactive construct within a $3 \mathrm{~min}$ application period (Fig. 9A). However, after $\mathrm{PI}(4,5) \mathrm{P}_{2}$ hydrolysis by the active Dr-VSP, a strong sensitizing effect of OAG was observed (Fig. 9B). The PKC inhibitor 19-31 amide in the patch pipette solution almost completely abolished TRPV1 sensitization by $1 \mu \mathrm{M}$ OAG (Fig. 9C).

We also tested whether we can detect the synergistic effect of $\mathrm{PI}(4,5) \mathrm{P}_{2}$ depletion and $\mathrm{PKC}$ activation at higher concentrations

of the PKC activator. As seen in Figure 9D, $10 \mu \mathrm{M}$ OAG was sufficient to induce potentiation of TRPV1, even in the cells expressing the phosphatase-inactive mutant. As before, depleting $\mathrm{PI}(4,5) \mathrm{P}_{2}$ by activating Dr-VSP amplified this potentiation. These results show cooperativity between $\mathrm{PI}(4,5) \mathrm{P}_{2}$ hydrolysis and $\mathrm{PKC}$ activation, but the requirement for $\mathrm{PI}(4,5) \mathrm{P}_{2}$ hydrolysis can be overcome by increasing the concentration of the PKC activator.

$\mathrm{PI}(4,5) \mathrm{P}_{2}$ was recently proposed to mediate indirect TRPV1 inhibition by preventing AKAP79/150-mediated PKA scaffolding to the channel (Jeske et al., 2011). We therefore tested whether TRPV1 sensitization by PKA could be potentiated by $\mathrm{PI}(4,5) \mathrm{P}_{2}$ depletion. The cell-permeable cAMP analog 8-BrcAMP at a concentration of $20 \mu \mathrm{M}$ elicited, on average, a $1.57 \pm$ 0.315-fold sensitization of TRPV1 after 3 min (Fig. 9E). PI(4,5) $\mathrm{P}_{2}$ depletion by Dr-VSP did not synergize with PKA activation, resulting in a $1.504 \pm 0.309$-fold sensitization in this group while completely inhibiting Kir2.1 currents (Fig. 9F).

In conclusion, we propose a model in which differential regulation of $\mathrm{PI}(4,5) \mathrm{P}_{2}$ and $\mathrm{PI}(4) \mathrm{P}$ levels by different PLC isoforms determines regulation of TRPV1 during sensitization and desensitization (Fig. 10).

\section{Discussion}

\section{Capsaicin-induced desensitization and the dependence of TRPV1 activity on phosphoinositides}

It has been known for decades that high concentrations of capsaicin reduce nerve responsiveness after an initial activation (Knotkova et al., 2008). Similarly, capsaicin-induced TRPV1 currents decline over time in the presence of extracellular $\mathrm{Ca}^{2+}$ (Caterina et al., 1997; Koplas et al., 1997). Based on the work of several laboratories with heterologously expressed TRPV1, it is an emerging view that depletion of $\mathrm{PI}(4,5) \mathrm{P}_{2}$ plays an important role in this phenomenon (Liu et al., 2005; Lishko et al., 2007; Lukacs et al., 2007; Gordon-Shaag et al., 2008; Yao and Qin, 2009).

Both $\mathrm{PI}(4,5) \mathrm{P}_{2}$ and its precursor $\mathrm{PI}(4) \mathrm{P}$ can support TRPV1 in excised patches (Lukacs et al., 2007; Klein et al., 2008). To clarify the role of how much $\mathrm{PI}(4,5) \mathrm{P}_{2}$ and $\mathrm{PI}(4) \mathrm{P}$ contributes to maintaining channel activity in intact cells, here we used a voltage-sensitive phosphatase that converts $\mathrm{PI}(4,5) \mathrm{P}_{2}$ to $\mathrm{PI}(4) \mathrm{P}$. Depolarizing pulses did not inhibit TRPV1 activity in cells expressing the phosphatase while strongly inhibiting Kir2.1 channels, activity of which depends specifically on $\mathrm{PI}(4,5) \mathrm{P}_{2}$ (Rohacs et al., 1999). These data are in agreement with our previous result showing that a rapamycin-inducible 5-phosphatase did not inhibit capsaicin-induced TRPV1 currents (Lukacs et al., 2007). On the other hand, we found that the rapamycin-inducible combined $5^{\prime}$ and $4^{\prime}$ phosphatase pseudojanin, which depletes both $\mathrm{PI}(4,5) \mathrm{P}_{2}$ and $\mathrm{PI}(4) \mathrm{P}$, inhibited TRPV1 currents. Our observations support the conclusion of a recent study where significant inhibition of TRPV1 was observed upon the combined dephosphorylation of $\mathrm{PI}(4,5) \mathrm{P}_{2}$ at the $4^{\prime}$ and $5^{\prime}$ position, but neither the removal of the $4^{\prime}$ nor $5^{\prime}$ phosphate alone inhibited the channel (Hammond et al., 2012). These data show that, in intact cells, TRPV1 requires either $\mathrm{PI}(4) \mathrm{P}$ or $\mathrm{PI}(4,5) \mathrm{P}_{2}$ for activity.

It should be noted that, in other studies, a similar, yet not identical, rapamycin-inducible 5-phosphatase inhibited TRPV1 (Klein et al., 2008; Yao and Qin, 2009). The reason for this discrepancy is unclear but could be the result of various reasons, including differences in the phosphatases used, which may warrant further investigations into the specificity of these molecular constructs.

We found that capsaicin induced a robust decrease in the plasma membrane levels of both $\mathrm{PI}(4,5) \mathrm{P}_{2}$ and $\mathrm{PI}(4) \mathrm{P}$ in isolated 


\section{A Maximal (pharmacological) TRPV1 activation}
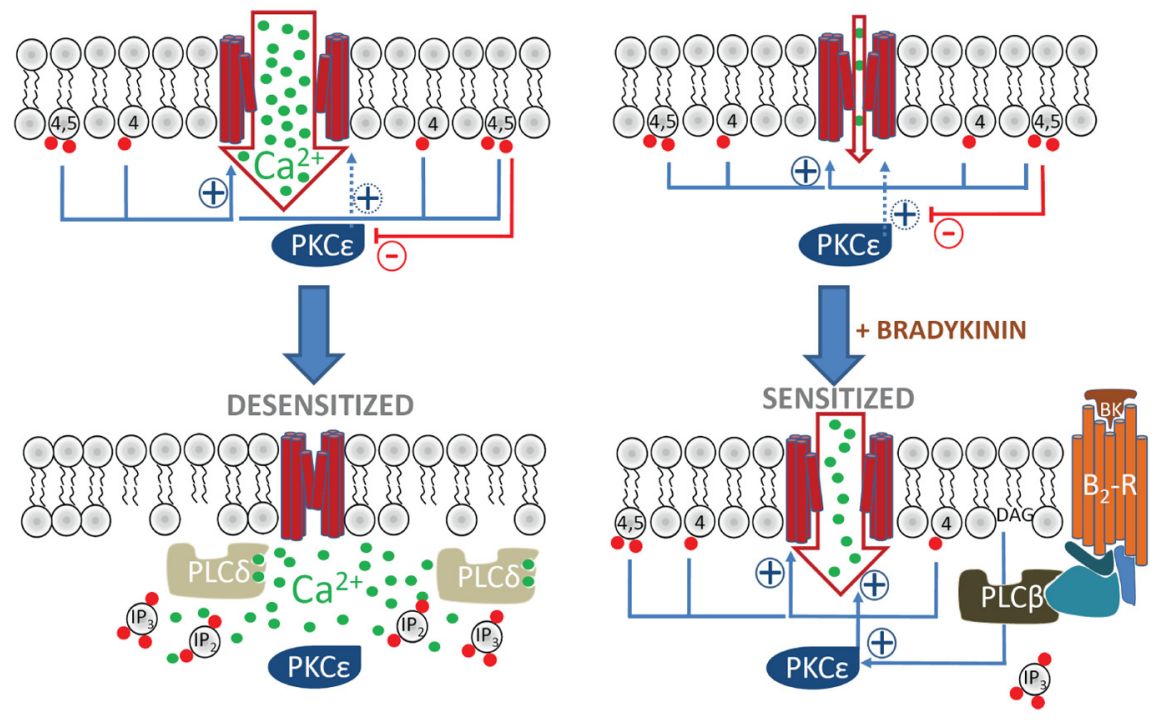

Figure 10. Model for the role of PLC activation in sensitization and desensitization of TRPV1. $A$, During maximal pharmacological activation of TRPV1, robust calcium influx activates highly calcium-sensitive PLC $\delta$ isoform(s), leading to substantial decrease of both $\mathrm{PI}(4,5) \mathrm{P}_{2}$ and $\mathrm{PI}(4) \mathrm{P}$ levels. This results in desensitization because channel activity generally depends on the presence of these lipids. The loss of phospholipids and the resultant decrease of TRPV1 activity dominate over the effect of a potential concomitant PKC activation. $\boldsymbol{B}$, During bradykinin-mediated sensitization, a selective decrease in $\mathrm{PI}(4,5) \mathrm{P}_{2}$, but not $\mathrm{PI}(4) \mathrm{P}$, allows for maintained TRPV1 activity, whereas the decreased PI $(4,5) \mathrm{P}_{2}$ levels synergize with the sensitizing effect of PKC phosphorylation, resulting in TRPV1 current potentiation.

DRG neurons. Because both these lipids may support channel activity, their combined reduction is quite likely to play an important role in channel desensitization. In accordance with this, dialysis of either $\mathrm{PI}(4,5) \mathrm{P}_{2}$ or $\mathrm{PI}(4) \mathrm{P}$ reduced TRPV1 desensitization to a similar extent in sensory neurons. It is noteworthy that, even in the presence of $\mathrm{PI}(4) \mathrm{P}$ or $\mathrm{PI}(4,5) \mathrm{P}_{2}$ in the patch pipette, there was substantial desensitization. This could potentially be the result of additional mechanisms, such as channel internalization (Sanz-Salvador et al., 2012) or activation of calcineurin (Docherty et al., 1996; Mohapatra and Nau, 2005) in desensitization. Internalization on this time scale is unlikely, however, because we found that supramaximal stimuli applied after desensitization induced TRPV1 current responses comparable to the amplitude of the first response (data not shown), in agreement with a recent study using a very similar protocol (Yao and Qin, 2009). It is also possible that the lipids have a partial effect because their diffusion through the narrow patch pipette could not keep up with their hydrolysis.

The most $\mathrm{Ca}^{2+}$-sensitive classical PLC isoforms are PLC $\delta$-s (Rebecchi and Pentyala, 2000). We have shown earlier that coexpression of PLC $\delta$ isoforms with TRPV1 (Lukacs et al., 2007) and TRPM8 (Rohacs et al., 2005) accelerated $\mathrm{Ca}^{2+}$-induced inhibition of the channel. We found that PLC $\delta 4$ was the dominant highly $\mathrm{Ca}^{2+}$-sensitive PLC isoform in DRG, even though there was a substantial expression of both PLC $\delta 1$ and $\delta 3$ as well, consistent with earlier findings (Daniels et al., 2009). To test the role of PLC $\delta$ s, we examined the desensitization kinetics of TRPV1 in $P L C \delta 4^{-1-}$ mice and found that desensitization was significantly less than in wild-type mice. The difference between wild-type and $P L C \delta 4^{-/-}$, however, was moderate. This is not surprising in light of the expression of the other two PLC $\delta$ isoforms; it is quite likely that their activity was sufficient to induce substantial desensitization. In addition, essentially all 13 PLC isoforms have some $\mathrm{Ca}^{2+}$ sensitivity, albeit less than PLC $\delta$ s, (Rebecchi and Pentyala, 2000); thus, they may also contribute to $\mathrm{PI}(4,5) \mathrm{P}_{2}$ breakdown upon the massive $\mathrm{Ca}^{2+}$ influx induced by capsaicin. Overall, the fact that desensitization was significantly altered in the PLC $\delta 4^{-1-}$ animals suggests that PLC $\delta$ s play a role in the desensitization of TRPV1.

\section{Bradykinin-induced sensitization}

The role of PKC is very well established in sensitization of TRPV1 currents by GPCR activation (Cesare et al., 1999; Bhave et al., 2003). The role of $\mathrm{PI}(4,5) \mathrm{P}_{2}$ depletion has been less straightforward. It was originally proposed that this lipid keeps TRPV1 under tonic inhibition, relief from which upon activation of PLC by bradykinin would play a major role in sensitization (Chuang et al., 2001). The demonstration by several laboratories, including ours that $\mathrm{PI}(4,5) \mathrm{P}_{2}$ does not inhibit, but rather activates, TRPV1 in excised patches (Stein et al., 2006; Lukacs et al., 2007; Kim et al., 2008b), seemed incompatible with this hypothesis. On the other hand, we also found that rapamycin-induced conversion of $\mathrm{PI}(4,5) \mathrm{P}_{2}$ to $\mathrm{PI}(4) \mathrm{P}$ potentiated TRPV1 currents activated by low concentrations of capsaicin in HEK cells and in Xenopus oocytes, moderate heat in HEK cells (Lukacs et al., 2007), and low pH in Xenopus oocytes (data not shown). Additionally, generating excess $\mathrm{PI}(4,5) \mathrm{P}_{2}$ by coexpression of a PIP5-kinase in Xenopus oocytes inhibited TRPV1 currents at low stimulation levels (Lukacs et al., 2007). Here we used another tool, Dr-VSP, to convert $\mathrm{PI}(4,5) \mathrm{P}_{2}$ to $\mathrm{PI}(4) \mathrm{P}$ and test the involvement of $\mathrm{PI}(4,5) \mathrm{P}_{2}$ in TRPV1 sensitization. Intriguingly, we could not evoke any reproducible potentiation of TRPV1 currents in HEK cells by depolarizing pulses alone. Depolarizing pulses in Dr-VSP-expressing cells, however, reliably potentiated the effect of submaximal activation of PKC by OAG. This points to a synergy between PKC stimulation and $\mathrm{PI}(4,5) \mathrm{P}_{2}$ reduction. Accordingly, dialysis of $\mathrm{PI}(4,5) \mathrm{P}_{2}$ or a $\mathrm{PKC}$ inhibitory peptide, but not $\mathrm{PI}(4) \mathrm{P}$, inhibited bradykinin-induced sensitization. What is the mechanism of the elusive inhibitory effect of $\mathrm{PI}(4,5) \mathrm{P}_{2}$ on TRPV1? Neither we nor other laboratories could detect inhibition by $\mathrm{PI}(4,5) \mathrm{P}_{2}$ in excised patches (Stein et al., 2006; Lukacs et al., 2007; Kim et al., 2008b). The slow time course of the development of the potentiating effect in most experiments also suggests an indirect effect. It was proposed that phosphoinositides regulate TRPV1 via Pirt (Kim et al., 2008a). Pirt, however, is specifically expressed in sensory neurons; thus, it is quite unlikely to be present either in HEK cells or Xenopus oocytes. A recent study, on the other hand, showed that $\mathrm{PI}(4,5) \mathrm{P}_{2}$ inhibits the purified TRPV1 in lipid vesicles, supporting a direct effect (Cao et al., 2013). Deciphering the mechanism of the inhibitory effect of $\mathrm{PI}(4,5) \mathrm{P}_{2}$ on TRPV1 in the context of sensitization requires further studies.

\section{Differential regulation of phosphoinositides by GPCRs and $\mathrm{Ca}^{2+}$ influx through TRPV1}

Why is $\mathrm{Ca}^{2+}$ influx through TRPV1 more effective than GPCR activation in depleting $\mathrm{PI}(4,5) \mathrm{P}_{2}$, and why does only $\mathrm{Ca}^{2+}$ influx 
through TRPV1 deplete PI(4)P substantially? Answering this question will require further studies, but some possible scenarios merit discussion. First, it is quite likely that the two stimuli activate different PLC isoforms. Bradykinin acts via Gq/11 proteins and activates PLC $\beta$-s (Tappe-Theodor et al., 2012), which are not activated by $\mathrm{Ca}^{2+}$ alone in a cellular context (Rebecchi and Pentyala, 2000). $\mathrm{Ca}^{2+}$ influx through TRPV1, on the other hand, likely activates mainly PLC $\delta$ isoforms. Generally, both $\mathrm{PI}(4,5) \mathrm{P}_{2}$ and PI(4)P are thought to be substrates of PLC. We are not aware of studies determining differences in phosphoinositide specificity among various isoforms, and it is possible that some display differences in selectivity between $\mathrm{PI}(4,5) \mathrm{P}_{2}$ and $\mathrm{PI}(4) \mathrm{P}$. It is also possible that the PLC isoforms activated by $\mathrm{Ca}^{2+}$ influx have higher overall activity than PLC $\beta$-s activated by bradykinin B2 receptors. Because PLCs generally prefer $\mathrm{PI}(4,5) \mathrm{P}_{2}$ over PI(4)P, a smaller extent of PLC activation by bradykinin could explain the differential change in response to GPCR stimulation. Consistent with this in rat DRG neurons bradykinin was found to evoke a moderate level of PLC activation (Liu et al., 2010). Finally, it is also possible that GPCRs activate a diverging signaling pathway leading to secondary increase of PI(4)P synthesis.

In principle, activation of PLC by either GPCR-s or by $\mathrm{Ca}^{2+}$ should evoke similar effects (i.e., hydrolysis of phosphoinositides, formation of $\mathrm{IP}_{3}$ and DAG, and the consequential activation of PKC). As mentioned earlier, PKC has been studied extensively in the context of sensitization, but minimal attention has been paid to it in the context of desensitization. A recent study showed that PKC is indeed activated during capsaicin-induced TRPV1 opening, as expected from PLC activation (Xu et al., 2012). In addition, capsaicin-induced desensitization could be reversed using very high concentrations of PMA (Mandadi et al., 2004). Overall, it is quite likely that PKC is activated during desensitization, and it may partially inhibit or slow down desensitization, but its effect under these conditions is overridden by the massive loss of PI(4,5) $\mathrm{P}_{2}$ and PI(4)P. Conversely, during GPCR activation, the effect of PKC-mediated sensitization dominates, as the changes in phosphoinositide levels synergize with it in two different ways: (1) relatively constant $\mathrm{PI}(4) \mathrm{P}$ levels play a permissive role in maintaining channel activity; and (2) the decrease in $\mathrm{PI}(4,5) \mathrm{P}_{2}$ levels potentiates the sensitizing effect of $\mathrm{PKC}$ activation.

$\mathrm{PI}(4,5) \mathrm{P}_{2}$ regulates a large number and variety of mammalian ion channels; how signaling specificity is achieved is not clear. Plasma membrane PI(4)P has long been considered merely as the precursor of $\mathrm{PI}(4,5) \mathrm{P}_{2}$. Its role as a separate, biologically important entity in the plasma membrane has just been recently proposed (Hammond et al., 2012). $\mathrm{PI}(4,5) \mathrm{P}_{2}$-sensitive ion channels show marked differences in lipid specificity; some, such as TRPV1 and $\mathrm{K}_{\mathrm{ATP}}$ (Shyng and Nichols, 1998), are also activated by PI(4)P. Other channels, such as TRPM8 (Rohacs et al., 2005), TRPV6 (Thyagarajan et al., 2008), and Kir2.1 (Rohacs et al., 1999), are not. Given these differences, differential regulation of $\mathrm{PI}(4,5) \mathrm{P}_{2}$ and $\mathrm{PI}(4) \mathrm{P}$ may also contribute to signaling specificity in regulation of other ion channels and thus be a more general signaling paradigm.

\section{References}

Balla A, Kim YJ, Varnai P, Szentpetery Z, Knight Z, Shokat KM, Balla T (2008) Maintenance of hormone-sensitive phosphoinositide pools in the plasma membrane requires phosphatidylinositol 4-kinase IIIalpha. Mol Biol Cell 19:711-721. CrossRef Medline

Balla T (2001) Pharmacology of phosphoinositides, regulators of multiple cellular functions. Curr Pharm Des 7:475-507. CrossRef Medline

Bhave G, Hu HJ, Glauner KS, Zhu W, Wang H, Brasier DJ, Oxford GS, Gereau
RW 4th (2003) Protein kinase C phosphorylation sensitizes but does not activate the capsaicin receptor transient receptor potential vanilloid 1 (TRPV1). Proc Natl Acad Sci U S A 100:12480-12485. CrossRef Medline Cao E, Cordero-Morales JF, Liu B, Qin F, Julius D (2013) TRPV1 channels are intrinsically heat sensitive and negatively regulated by phosphoinositide lipids. Neuron 77:667-679. CrossRef Medline

Caterina MJ, Schumacher MA, Tominaga M, Rosen TA, Levine JD, Julius D (1997) The capsaicin receptor: a heat-activated ion channel in the pain pathway. Nature 389:816-824. CrossRef Medline

Caterina MJ, Leffler A, Malmberg AB, Martin WJ, Trafton J, Petersen-Zeitz KR, Koltzenburg M, Basbaum AI, Julius D (2000) Impaired nociception and pain sensation in mice lacking the capsaicin receptor. Science 288 : 306-313. CrossRef Medline

Cesare P, Dekker LV, Sardini A, Parker PJ, McNaughton PA (1999) Specific involvement of PKC-epsilon in sensitization of the neuronal response to painful heat. Neuron 23:617-624. CrossRef Medline

Chuang HH, Prescott ED, Kong H, Shields S, Jordt SE, Basbaum AI, Chao MV, Julius D (2001) Bradykinin and nerve growth factor release the capsaicin receptor from $\operatorname{PtdIns}(4,5) \mathrm{P}_{2}$-mediated inhibition. Nature 411: 957-962. CrossRef Medline

Cockcroft S (2006) The latest phospholipase C, PLC $\eta$, is implicated in neuronal function. Trends Biochem Sci 31:4-7. CrossRef Medline

Daniels RL, Takashima Y, McKemy DD (2009) Activity of the neuronal cold sensor TRPM8 is regulated by phospholipase $\mathrm{C}$ via the phospholipid phosphoinositol 4,5-bisphosphate. J Biol Chem 284:1570-1582. CrossRef Medline

Docherty RJ, Yeats JC, Bevan S, Boddeke HW (1996) Inhibition of calcineurin inhibits the desensitization of capsaicin-evoked currents in cultured dorsal root ganglion neurones from adult rats. Pflugers Arch 431:828837. CrossRef Medline

Du X, Zhang H, Lopes C, Mirshahi T, Rohacs T, Logothetis DE (2004) Characteristic interactions with phosphatidylinositol 4,5-bisphosphate determine regulation of Kir channels by diverse modulators. J Biol Chem 279:37271-37281. CrossRef Medline

Fukami K, Nakao K, Inoue T, Kataoka Y, Kurokawa M, Fissore RA, Nakamura K, Katsuki M, Mikoshiba K, Yoshida N, Takenawa T (2001) Requirement of phospholipase C- $\delta 4$ for the zona pellucida-induced acrosome reaction. Science 292:920-923. CrossRef Medline

Gamper N, Rohacs T (2012) Phosphoinositide sensitivity of ion channels, a functional perspective. Subcell Biochem 59:289-333. CrossRef Medline

Gordon-Shaag A, Zagotta WN, Gordon SE (2008) Mechanism of $\mathrm{Ca}^{2+}$ dependent desensitization in TRP channels. Channels (Austin) 2:125129. CrossRef Medline

Hammond GR, Fischer MJ, Anderson KE, Holdich J, Koteci A, Balla T, Irvine RF (2012) PI4P and PI $(4,5) \mathrm{P}_{2}$ are essential but independent lipid determinants of membrane identity. Science 337:727-730. CrossRef Medline

Hossain MI, Iwasaki H, Okochi Y, Chahine M, Higashijima S, Nagayama K, Okamura Y (2008) Enzyme domain affects the movement of the voltage sensor in ascidian and zebrafish voltage-sensing phosphatases. J Biol Chem 283:18248-18259. CrossRef Medline

Hucho T, Levine JD (2007) Signaling pathways in sensitization: toward a nociceptor cell biology. Neuron 55:365-376. CrossRef Medline

Jeske NA, Por ED, Belugin S, Chaudhury S, Berg KA, Akopian AN, Henry MA, Gomez R (2011) A-kinase anchoring protein 150 mediates transient receptor potential family $\mathrm{V}$ type 1 sensitivity to phosphatidylinositol-4,5-bisphosphate. J Neurosci 31:8681-8688. CrossRef Medline

Kim AY, Tang Z, Liu Q, Patel KN, Maag D, Geng Y, Dong X (2008a) Pirt, a phosphoinositide-binding protein, functions as a regulatory subunit of TRPV1. Cell 133:475-485. CrossRef Medline

Kim D, Cavanaugh EJ, Simkin D (2008b) Inhibition of transient receptor potential A1 channel by phosphatidylinositol-4,5-bisphosphate. Am J Physiol Cell Physiol 295:C92-C99. CrossRef Medline

Klein RM, Ufret-Vincenty CA, Hua L, Gordon SE (2008) Determinants of molecular specificity in phosphoinositide regulation. phosphatidylinositol $(4,5)$-bisphosphate $\left(\mathrm{PI}(4,5) \mathrm{P}_{2}\right)$ is the endogenous lipid regulating TRPV1. J Biol Chem 283:26208-26216. CrossRef Medline

Knotkova H, Pappagallo M, Szallasi A (2008) Capsaicin (TRPV1 agonist) therapy for pain relief: farewell or revival? Clin J Pain 24:142-154. CrossRef Medline

Koplas PA, Rosenberg RL, Oxford GS (1997) The role of calcium in the 
desensitization of capsaicin responses in rat dorsal root ganglion neurons. J Neurosci 17:3525-3537. Medline

Korzeniowski MK, Popovic MA, Szentpetery Z, Varnai P, Stojilkovic SS, Balla T (2009) Dependence of STIM1/Orail-mediated calcium entry on plasma membrane phosphoinositides. J Biol Chem 284:21027-21035. CrossRef Medline

Li Y, Gamper N, Hilgemann DW, Shapiro MS (2005) Regulation of Kv7 (KCNQ) $\mathrm{K}^{+}$channel open probability by phosphatidylinositol 4,5bisphosphate. J Neurosci 25:9825-9835. CrossRef Medline

Lishko PV, Procko E, Jin X, Phelps CB, Gaudet R (2007) The ankyrin repeats of TRPV1 bind multiple ligands and modulate channel sensitivity. Neuron 54:905-918. CrossRef Medline

Liu B, Zhang C, Qin F (2005) Functional recovery from desensitization of vanilloid receptor TRPV1 requires resynthesis of phosphatidylinositol 4,5-bisphosphate. J Neurosci 25:4835-4843. CrossRef Medline

Liu B, Linley JE, Du X, Zhang X, Ooi L, Zhang H, Gamper N (2010) The acute nociceptive signals induced by bradykinin in rat sensory neurons are mediated by inhibition of $\mathrm{M}$-type $\mathrm{K}^{+}$channels and activation of $\mathrm{Ca}^{2+}$-activated $\mathrm{Cl}^{-}$channels. J Clin Invest 120:1240-1252. CrossRef Medline

Logothetis DE, Nilius B (2007) Dynamic changes in phosphoinositide levels control ion channel activity. Pflugers Arch 455:1-3. CrossRef Medline

Lukacs V, Thyagarajan B, Varnai P, Balla A, Balla T, Rohacs T (2007) Dual regulation of TRPV1 by phosphoinositides. J Neurosci 27:7070-7080. CrossRef Medline

Mandadi S, Numazaki M, Tominaga M, Bhat MB, Armati PJ, Roufogalis BD (2004) Activation of protein kinase C reverses capsaicin-induced calcium-dependent desensitization of TRPV1 ion channels. Cell Calcium 35:471-478. CrossRef Medline

Mohapatra DP, Nau C (2005) Regulation of $\mathrm{Ca}^{2+}$-dependent desensitization in the vanilloid receptor TRPV1 by calcineurin and cAMPdependent protein kinase. J Biol Chem 280:13424-13432. CrossRef Medline

Murata Y, Iwasaki H, Sasaki M, Inaba K, Okamura Y (2005) Phosphoinositide phosphatase activity coupled to an intrinsic voltage sensor. Nature 435:1239-1243. CrossRef Medline

Nilius B, Owsianik G, Voets T (2008) Transient receptor potential channels meet phosphoinositides. EMBO J 27:2809-2816. CrossRef Medline

Quinn KV, Behe P, Tinker A (2008) Monitoring changes in membrane phosphatidylinositol 4,5-bisphosphate in living cells using a domain from the transcription factor tubby. J Physiol 586:2855-2871. CrossRef Medline

Raisinghani M, Pabbidi RM, Premkumar LS (2005) Activation of transient receptor potential vanilloid 1 (TRPV1) by resiniferatoxin. J Physiol 567: 771-786. CrossRef Medline

Rebecchi MJ, Pentyala SN (2000) Structure, function, and control of phosphoinositide-specific phospholipase C. Physiol Rev 80:1291-1335. Medline

Rohacs T (2009) Phosphoinositide regulation of non-canonical transient receptor potential channels. Cell Calcium 45:554-565. CrossRef Medline

Rohács T, Chen J, Prestwich GD, Logothetis DE (1999) Distinct specificities of inwardly rectifying $\mathrm{K}^{+}$channels for phosphoinositides. J Biol Chem 274:36065-36072. CrossRef Medline

Rohács T, Lopes CM, Michailidis I, Logothetis DE (2005) $\mathrm{PI}(4,5) \mathrm{P}_{2}$ regu- lates the activation and desensitization of TRPM8 channels through the TRP domain. Nat Neurosci 8:626-634. CrossRef Medline

Roy A, Levine TP (2004) Multiple pools of phosphatidylinositol 4-phosphate detected using the pleckstrin homology domain of Osh2p. J Biol Chem 279:44683-44689. CrossRef Medline

Sanz-Salvador L, Andrés-Borderia A, Ferrer-Montiel A, Planells-Cases R (2012) Agonist- and $\mathrm{Ca}^{2+}$-dependent desensitization of TRPV1 targets the receptor to lysosomes for degradation. J Biol Chem 287:19462-19471. CrossRef Medline

Shyng SL, Nichols CG (1998) Membrane phospholipid control of nucleotide sensitivity of KATP channels. Science 282:1138-1141. CrossRef Medline

Stein AT, Ufret-Vincenty CA, Hua L, Santana LF, Gordon SE (2006) Phosphoinositide 3-kinase binds to TRPV1 and mediates NGF-stimulated TRPV1 trafficking to the plasma membrane. J Gen Physiol 128:509-522. CrossRef Medline

Suh BC, Hille B (2008) $\mathrm{PIP}_{2}$ is a necessary cofactor for ion channel function: how and why? Annu Rev Biophys 37:175-195. CrossRef Medline

Suh BC, Leal K, Hille B (2010) Modulation of high-voltage activated $\mathrm{Ca}^{2+}$ channels by membrane phosphatidylinositol 4,5-bisphosphate. Neuron 67:224-238. CrossRef Medline

Szolcsányi J (2004) Forty years in capsaicin research for sensory pharmacology and physiology. Neuropeptides 38:377-384. CrossRef Medline

Tappe-Theodor A, Constantin CE, Tegeder I, Lechner SG, Langeslag M, Lepcynzsky P, Wirotanseng RI, Kurejova M, Agarwal N, Nagy G, Todd A, Wettschureck N, Offermanns S, Kress M, Lewin GR, Kuner R (2012) $\mathrm{G} \alpha(\mathrm{q} / 11)$ signaling tonically modulates nociceptor function and contributes to activity-dependent sensitization. Pain 153:184-196. CrossRef Medline

Thyagarajan B, Lukacs V, Rohacs T (2008) Hydrolysis of phosphatidylinositol 4,5-bisphosphate mediates calcium-induced inactivation of TRPV6 channels. J Biol Chem 283:14980-14987. CrossRef Medline

Tominaga M, Caterina MJ, Malmberg AB, Rosen TA, Gilbert H, Skinner K, Raumann BE, Basbaum AI, Julius D (1998) The cloned capsaicin receptor integrates multiple pain-producing stimuli. Neuron 21:531-543. CrossRef Medline

Xu YP, Zhang JW, Li L, Ye ZY, Zhang Y, Gao X, Li F, Yan XS, Liu ZG, Liu LJ, Cao XH (2012) Complex regulation of capsaicin on intracellular second messengers by calcium dependent and independent mechanisms in primary sensory neurons. Neurosci Lett 517:30-35. CrossRef Medline

Yao J, Qin F (2009) Interaction with phosphoinositides confers adaptation onto the TRPV1 pain receptor. PLoS Biol 7:e46. CrossRef Medline

Yudin YK, Tamarova ZA, Ostrovskaya OI, Moroz LL, Krishtal OA (2004) RFa-related peptides are algogenic: evidence in vitro and in vivo. Eur J Neurosci 20:1419-1423. CrossRef Medline

Yudin Y, Lukacs V, Cao C, Rohacs T (2011) Decrease in phosphatidylinositol 4,5-bisphosphate levels mediates desensitization of the cold sensor TRPM8 channels. J Physiol 589:6007-6027. CrossRef Medline

Zhang H, Craciun LC, Mirshahi T, Rohács T, Lopes CM, Jin T, Logothetis DE (2003) PIP $_{2}$ activates KCNQ channels, and its hydrolysis underlies receptor-mediated inhibition of $\mathrm{M}$ currents. Neuron 37:963-975. CrossRef Medline

Zimmermann K, Hein A, Hager U, Kaczmarek JS, Turnquist BP, Clapham DE, Reeh PW (2009) Phenotyping sensory nerve endings in vitro in the mouse. Nat Protoc 4:174-196. CrossRef Medline 